\title{
SEX MODERATES THE RELATIONSHIP BETWEEN AORTIC STIFFNESS, COGNITION AND CEREBROVASCULAR REACTIVITY IN HEALTHY OLDER ADULTS
}

Dalia Sabra 1, 2, 3, $5 *$; Brittany Intzandt 2, 3, 11, 12 ; Laurence Desjardins-Crepeau 2,3 ; Antoine Langeard 2,3,5 Christopher J. Steele 8, 9, 11 ; Frédérique Frouin 4 Richard D. Hoge 7, 8; Louis Bherer $2,3,5$, and Claudine J. Gauthier 2, 10, 11

${ }^{1}$ Department of Biomedical Science, Faculty of Medicine, Université de Montreal, Montreal, QC, Canada

${ }^{2}$ Research Center, Montreal Heart Institute, Montreal, QC, Canada

3 Centre de recherche de l'Institut Universitaire de Gériatrie de Montréal (CRIUGM), Montréal, QC, Canada

${ }^{4}$ LITO laboratory, Inserm, Institut Curie, Orsay, France

${ }^{5}$ Department of Medicine, Universite de Montreal, Montreal, QC, Canada

${ }^{6}$ Montreal Neurological Institute, Montreal, QC, Canada

${ }^{7}$ Department of Neurology and Neurosurgery, McGill University, Montreal, QC, Canada

${ }^{8}$ Department of Neurology, Max Planck Institute for Human Cognitive and Brain Sciences, Leipzig, Germany

${ }^{9}$ Department of Psychology, Concordia University, Montreal, QC, Canada

${ }^{\circ}$ Physics Department, Concordia University, Montreal, QC, Canada

${ }^{1}$ PERFORM Centre, Concordia University, Montreal, QC, Canada

${ }_{12}^{2}$ INDI Department, Concordia University, Montreal, QC, Canada

\section{Corresponding Author:}

Claudine J. Gauthier, PhD

Title: Assistant Professor, Physics

Office: L-SP 365-06 Richard J.Renaud Science Complex, 7141 Sherbrooke W.

Phone: (514) 848-2424 ext. 2193

Email: claudine.gauthier@,concordia.ca 
Cardiovascular disease (CVD)

Magnetic resonance imaging (MRI)

Arterial spin labelling (ASL)

Pulse wave velocity (PWV)

Cerebrovascular reactivity (CVR)

Hemoglobin (HGB)

Hematocrit (HCT)

Cerebrospinal fluid (CSF)

Voxel based morphometry (VBM)

Pulse pressure (PP)

Arterial stiffness (AS)

Cerebral blood flow (CBF)

Executive function (EF)

Positron-emission tomography (PET)

Transcranial doppler (TCD)

Processing speed (PS)

Mini-mental state examination (MMSE)

Color-word interference test (CWIT)

Trail making test part B (TMT-B)

Signal-to-noise ratio (SNR)

White matter hyperintensities (WMH)

Pseudo-continuous arterial spin labeling (pCASL)

Fluid-attenuated inversion recovery (FLAIR)

Nitric oxide (NO) 


\title{
Highlights
}

- This study investigates the role of sex on cerebrovascular measures of brain health and congition

- Sex moderates the relationship between PWV, cerebrovascular reactivity and cognition

- Hematocrit influences the sex differences observed

\begin{abstract}
It is well established that sex differences exist in the manifestation of cardiovascular diseases. Arterial stiffness (AS) has been associated with changes in cerebrovascular reactivity (CVR) and cognitive decline in aging. Specifically, older adults with increased AS show a decline on executive function (EF) tasks. Interestingly, the relationship between AS and CVR is more complex, where some studies show decreased CVR with increased AS, and others demonstrate preserved CVR despite higher AS. We investigated the possible role of sex and hematocrit (HCT) on these hemodynamic relationships. Acquisitions were completed in 48 older adults. Dual-echo pCASL data were collected during a hypercapnia challenge. Aortic PWV data was acquired using cine phase contrast velocity series. A moderation model test revealed that sex moderated the relationship between PWV and CVR and PWV and EF. In addition, there was a significant effect of HCT on the sex differences observed in the moderation effect on EF. Together, our results indicate that the relationships between PWV, CVR and EF are in part mediated by sex and HCT.
\end{abstract}

Keywords = Arterial stiffness; cerebrovascular reactivity; magnetic resonance imaging; arterial spin labeling; sex; hematocrit. 


\section{Introduction}

Cardiovascular diseases (CVD) are the leading cause of death worldwide in males and females, and on average, someone dies of CVD every 38 seconds, resulting in 2,303 deaths per day due to CVDs (Members et al. 2010). Cardiovascular risk is highly sex-dependent, as males exhibit greater incidences and prevalence than females (Petrea et al. 2009; Appelros et al. 2009). However, the risk of heart disease is often underestimated in females due to the misperception that females are protected against CVDs. This could be explained, in part, by the findings of epidemiological studies indicating that premenopausal females are relatively protected from CVDs when compared to age-matched males (Coutinho 2014; Ellekjaer et al. 1997; DuPont et al. 2019). Yet, the incidence of CVD increases disproportionately in females after menopause (Coutinho 2014; Ellekjaer et al. 1997; DuPont et al. 2019), typically 7 to 10 years later, and is the most common cause of death in females over the age of 65 years (Maas et al. 2010). This calls for further understanding of the underlying mechanisms for sex differences involved in the development of cardiovascular diseases. The pathophysiology underlying CVDs is thought to differ depending on the presence of sex hormones leading to differences in vascular properties, including differences in vascular tone (DuPont et al. 2019). Notably, estrogen is thought to have a positive effect on the inner layer of the artery wall, helping to keep blood vessels flexible, and allowing them to relax and expand to accommodate increases in blood flow (Maas et al. 2010; Towfighi et al. 2009). Many of these effects are mediated or influenced by nitric oxide (NO), a highly reactive gaseous mediator that plays a pivotal role in regulating vessel wall homeostasis (Cannon 1998; McNeill et al. 2002). Consequently, a decline in estrogen in postmenopausal females may lead to arterial stiffening (AS) and thus contribute to the increased prevalence of CVD in females in later life (Pepine et al. 2006; Orshal and Khalil 2004; Shaw et al. 2006). Moreover, recent work suggests a potential protective role of testosterone against AS. Specifically, low testosterone levels in males is associated with greater AS (Kyriazis et al. 2011) and augmentation index, an indirect measure of carotid stiffness (Corrigan et al. 2015).

It is well established that elevated AS is an independent predictor of CVD (Mitchell 2009). The elasticity of large arteries allows for the dampening of the arterial pressure waveform, transforming the pulsatile flow at the heart level into steady blood flow into the micro-vessels (Scuteri et al. 2011; Iulita et al. 2018; Badji et al. 2019). Unfortunately, during aging, large arteries (e.g the aorta, the carotids etc) become stiffer and show a reduced capacity to dampen the arterial pressure waveform (Badji et al. 2019). With aging, the elastic properties of blood vessel walls are known to deteriorate (Novak 2012). In particular, the ratio between elastin and collagen changes in favor of collagen, making the vessel stiffer (Novak 2012). Considering the impact of AS on vascular health, non-invasive methods have been developed to measure it, among which pulse wave velocity (PWV) is considered to be the gold standard (Van Bortel et al. 2012).

The impact of AS differs considerably between males and females because of numerous endogenous factors such as the previously mentioned sex hormones and biochemical properties of the arteries (Rossi et al. 2011; Segers et al. 2007). For instance, it has been shown that aged male and female monkeys develop similar levels of AS but a decrease in elastin was noted only in male monkeys (Qiu et al. 2007). In addition, dyslipidemia and glucose contribute to a modest increase in arterial stiffness only in females (Kim et al. 2014). Moreover, it has been shown that the association between AS and mortality is almost two-fold higher in females compared to males after menopause (Regnault et al. 2012), showing probably differences in pathophysiological mechanisms. 
However, some of the sex-related differences observed may be in part due to differences in how sex-specific physiological factors (e.g HCT) affect the measures themselves. For example, recent work suggests that hemodynamic measures, such as PWV, may be affected by differences in the concentration of HCT. Males and females typically have different HCT levels (Yip et al. 1984; Vahlquist and Others 1950; Garn et al. 1975), and whole blood viscosity (hematocrit and plasma viscosity) has been shown to be positively correlated with certain cardiovascular disease factors and measures of vascular function (Parkhurst et al. 2012; Bonithon-Kopp et al. 1993; Levenson et al. 1987). Thus, this raises the possibility that a portion of the sex effects observed in the literature could be mediated, in part, by differences in HGB levels.

AS is also associated with downstream organ damage, especially in high-flow organs such as the brain (Pase et al. 2016; Iulita et al. 2018; Mitchell 2009; O'Rourke and Safar 2005; Badji et al. 2019). Indeed, high pulsatile flow following AS may damage cerebral microvessels, thus, leading progressively to changes in cerebral blood flow (CBF) (Singer et al. 2013; Tarumi et al. 2013; Tarumi et al. 2011). Increased stiffness is also associated with changes in cerebrovascular reactivity (CVR), defined as the ability of microvessels to increase blood flow in response to a vasodilatory stimulus (DuBose et al. 2018; Jefferson et al. 2018). It can be hypothesized that increased stiffening of the aorta and higher pulse pressure may lead to damage in downstream vessels from the damaging effects of the pressure amplification caused by large artery stiffness. Therefore, greater artery stiffness may contribute to the impaired ability of the cerebrovasculature to dilate maximally to augment cerebral blood flow (CBF) in older adults. Yet, the literature has found conflicting results, where some have reported reductions in CVR among older adults with greater aortic stiffness using positron-emission tomography (PET) and transcranial doppler (TCD) (DuBose et al. 2018; Jaruchart et al. 2016), while others demonstrate preserved CVR in the presence of higher aortic PWV (Jefferson et al. 2018; Zhu et al. 2013) using arterial spin labeling (ASL), an MRI technique for noninvasive quantification of CBF. Because these imaging modalities (TCD, PET, ASL) are sensitive to CVR arising from different vessel sizes, these results indicate that the relationship between PWV and CVR is complex. With the evidence that sex differences exist in the manifestation of AS, it is unclear if the conflicting results could partly be due to sex-specific characteristics.

Another consequence of a stiffer vascular network is a change in cognitive function (Singer et al. 2014). There is accumulating evidence from cross-sectional studies that AS is associated with the pathogenesis of cognitive decline in both males and females (Singer et al. 2014; Elias et al. 2009; Fukuhara et al. 2006) in age-sensitive domains such as processing speed (PS), verbal memory, and executive functions (EF) (Poels et al. 2007; Watson et al. 2011). Interestingly, associations between PWV, impaired CVR and severity of dementia have also been established (Silvestrini et al. 2006). Indeed, reduced reactivity has been linked to decreased executive functioning, memory, global cognition, and attention outcomes (Haratz et al. 2015). Interestingly, evidence for sex differences has been reported in a number of specific cognitive domains (Halpern and LaMay 2000). Yet, no study to date has investigated the role of sex on the relationship between cognition and neuroimaging markers of brain hemodynamics. Thus, the purpose of this study is to clarify the impact of sex-related differences on the link between PWV, cognitive performance and CVR and the relative contribution of HCT on these relationships. 


\section{Methods}

\subsection{Participants}

Fifty-four healthy older adults (17 males, mean age $63 \pm 5$ years) completed a magnetic resonance imaging (MRI) session. Participants were recruited through a participant database at the Centre de recherche de l'Institut universitaire de gériatrie de Montréal and from Laboratoire D'Etude de la Santé cognitive des Ainés. Inclusion criteria for participation included being in the age range of 55 to 75 years, approval by a geriatrician to participate, non-smoker, no evidence of cognitive impairment as determined through cognitive tests conducted by a neuropsychologist, and MRI compatibility. In addition, the Mini Mental Status Examination (MMSE) was administered, a global cognitive screening tool used for dementia. Participants with scores of less than 26 (out of 30) were excluded (Kurlowicz and Wallace 1999; Gauthier et al. 2015) (no participant was excluded from the sample for this reason). Other exclusion criteria included individuals taking prescription medication known to be vasoactive (e.g. anti-hypertensive drugs, statins, etc.), presence of cardiac disease, hypertension (including use of anti-hypertensive medication), neurological or psychiatric illnesses, diabetes, asthma, thyroid disorders, smoking within the last 5 years, or excessive drinking (more than two drinks per day). All procedures were approved by Comité mixte d'éthique de la recherche du Regroupement Neuroimagerie/Québec and were conducted according to the Declaration of Helsinki. All participants provided written informed consent. From all participants that were recruited, a total of 48 older adults ( 17 males, mean age $63 \pm 5$ years) were included in the analysis. The six participants were excluded as outliers since they were more than 2.5 standard deviations above or below the mean of PWV values. Exclusion of these participants did not change the results.

\subsection{Cognitive Functioning}

Cognitive function was assessed with a comprehensive neuropsychological battery consisting of the following cognitive tests: Similarities, Digit Span Backwards, Digit Span forward, Digit Symbol, Color-word interference test (CWIT), and Trail Making Tests, parts A and B (Gauthier et al. 2013; Intzandt et al. 2019).

A composite score for executive function (EF) was calculated using four cognitive tests from the neuropsychological battery that included the CWIT Inhibition and switching conditions, Trail making test part B and the digit span backward. The trail making test part B (TMT-B), the CWIT inhibition condition and the CWIT switching condition were timed in seconds where a low score (faster response) indicates better functioning. The digit span backward was calculated as the number of successful trials where a higher score indicates better EF.

Individual raw scores for each test were transformed into z-scores. The scores that were response time were multiplied by -1 so that a higher EF composite score indicates better cognitive functioning. Cronbach's alpha was used as a test of reliability to look at the internal consistency for the group of variables. A Cronbach alpha of 0.789 was computed for executive function showing good internal consistency.

\subsection{Hypercapnia}


As previously described (Gauthier et al. 2015; Gauthier et al. 2013; Intzandt et al. 2019), the hypercapnic manipulation was completed with a computer-controlled gas system with a sequential gas delivery circuit (Respiract ${ }^{\mathrm{TM}}$, Thornhill Research Inc., Toronto, Canada). The hypercapnic manipulation consisted of two, 2-minute blocks of hypercapnia, with 2 minutes of air before and after each hypercapnia block. End-tidal partial pressure of CO2 (ETCO2) was targeted at $40 \mathrm{mmHg}$ at baseline and $45 \mathrm{mmHg}$ during the hypercapnia blocks. End-tidal partial pressure of $\mathrm{O} 2$ (ETO2) was targeted to be $100 \mathrm{mmHg}$ throughout the experiment. Participants breathed through a soft plastic mask that was firmly placed on their face with adhesive tape (Tegaderm 3M Healthcare, St. Paul MN) to ensure that no leaks were present. Participants completed the breathing manipulation once prior to being in the scanner to ensure adequate comfort levels, and once after the MRI session.

\subsection{MRI acquisition}

All acquisitions were completed on a Siemens TIM Trio 3T MRI system (Siemens Medical Solutions, Erlangen, Germany). A 32-channel vendor-supplied head coil was used for all acquisitions. An anatomical $1 \mathrm{~mm}^{3}$ MPRAGE acquisition (TR/TE/flip angle $=300 \mathrm{~ms} / 3 \mathrm{~ms} / 90^{\circ}$, 256x240 matrix) was acquired for the registration process from native to standard space, and to measure grey matter partial volume. A fluid attenuation inversion recovery (FLAIR) acquisition with the parameters: TR/TE/flip angle $9000 \mathrm{~ms} / 107 \mathrm{~ms} / 120^{\circ}$, an inversion time of $2500 \mathrm{~ms}, 512$ x 512 matrix for an in-plane resolution of $0.43 \times 0.43 \mathrm{~mm}$ and 25 slices of $4.8 \mathrm{~mm}$ was used to estimate the presence and severity of white-matter hyperintensities. In addition, a pseudo-continuous arterial spin labeling (pCASL) acquisition was acquired, providing simultaneous BOLD contrast using dual-echo readouts (TR/TE1/TE2/flip angle $=2000 \mathrm{~ms} / 10$ $\mathrm{ms} / 30 \mathrm{~ms} / 90^{\circ}$ ) with $4 \times 4 \times 7 \mathrm{~mm}^{3}$ voxels, $64 \times 64$ matrix and 11 slices, post-label delay $=900 \mathrm{~ms}$, tag duration $=1.5 \mathrm{~s}$, and a $100 \mathrm{~mm}$ gap during a hypercapnia challenge $(5 \mathrm{mmHg}$ end-tidal $\mathrm{CO} 2$ change, iso-oxic during two, 2 min blocks).

\subsection{Aortic Exam}

As previously described (Gauthier et al. 2015; Intzandt et al. 2019), during the MRI session a thoracic aortic exam was also acquired using simultaneous brachial pressure recording (Model 53,000, Welch Allyn, Skaneateles Falls, NY USA) using a 24- element spine matrix coil. Black blood turbo spin echo sagittal oblique images were acquired to visualize the aortic arch (TR/TE/flip angle: $700 \mathrm{~ms} / 6.5 \mathrm{~ms} / 180^{\circ}, 1.4 \times 1.4 \mathrm{~mm}^{2}$ in-plane resolution, 2 slices at $7.0 \mathrm{~mm}$ ). A perpendicular plane to the ascending and descending aorta was defined from these images. A cine phase-contrast velocity encoded series was collected (TR/TE/flip angle: $28.6 \mathrm{~ms} / 1.99$ $\mathrm{ms} / 30^{\circ}, 1.5 \times 1.5 \times 5.5 \mathrm{~mm}^{3}$ ) during 60 cardiac cycles in three segments, with velocity encoding of $180 \mathrm{~cm} / \mathrm{s}$ through plane. A series of cine FLASH images were acquired within the same plane with the following parameters: TR/TE/flip angle: $59 \mathrm{~ms} / 3.44 \mathrm{~ms} / 15^{\circ}$, with $1.2 \times 1.2 \mathrm{~mm}^{2}$ in-plane resolution and a single slice of $6 \mathrm{~mm}, 60$ cardiac phases, acquired in 8 segments.

\subsection{Data Analysis}


Preprocessing of TI-weighted MPRAGE images were done using voxel based morphometry (VBM) in SPM's Computational Anatomy Toolbox (CAT) 12 (Penny et al. 2011; Ashburner and Friston 2000; Gaser 2016) to segment grey matter, white matter and cerebrospinal fluid (CSF). The registration matrix from T1 space to MNI space was calculated as part of the VBM pipeline Co-registration of native CVR data was done using a non-linear rigid registration with ANTS (Avants et al. 2008) with a b-spline interpolation to bring them from native to individual T1 space. CAT12 was then used to register from T1 to standard space using a Gaussian smoothing kernel of $8 \mathrm{~mm}$ and a non-linear registration with 12 degrees of freedom as previously described. (Intzandt et al. 2019)

\subsection{Resting CBF Analysis}

Resting CBF was calculated as previously described (Intzandt et al. 2019). CSF masks were created individually for each older adult to use as a CSF M0 for CBF quantification. 10 voxels were manually chosen in the same axial slice for each participant, within the lateral ventricles. The M0 was then estimated from the control time series and estimated using a monoexponential recovery with a T1 value of $1.65 \mathrm{~s}$. Due to varying anatomical structures, each CSF mask was visually inspected to ensure that the region of interest was located in the ventricles. The Bayesian inference for arterial spin labeling MRI toolbox (BASIL) was used for CBF quantification with the following parameters: labeling: cASL/pcASL; bolus duration: constant (1.5s), post label delay: 0.9s; calibration image: average of the control images; reference tissue type: CSF; mask: CSF mask for each participant; CSF TI: $4.3 \mathrm{~s}$; TE:10 ms; T2: $750 \mathrm{~ms}$; blood T2: $150 \mathrm{~ms}$; arterial transit time: $1.3 \mathrm{~s}, \mathrm{~T} 1: 1.3 \mathrm{~s}$, TI blood: $1.65 \mathrm{~s}$, inversion efficiency: 0.85 (Intzandt et al. 2019).

\subsection{CVR Analysis}

CBF-CVR was processed using Neurolens2 (Gauthier et al. 2013; Intzandt et al. 2019). Preprocessing of all raw images included motion correction and spatial smoothing using a $6 \mathrm{~mm}$ Gaussian kernel. The CBF signal was isolated from the first series of echoes using linear surround subtraction (Liu and Wong 2005; Gauthier and Hoge 2012; Gauthier et al. 2012; Intzandt et al. 2019). The CBF fractional change during hypercapnia was obtained by fitting a general linear model to the CBF signal and dividing the estimated effect size by the estimated constant term. Glover's parameters (1999) (Glover 1999) for a single-gamma hemodynamic response function were used when fitting the linear models, which included linear, quadratic, and third order polynomials representing baseline signal and drifts. The CBF percent change obtained was then divided by the average end-tidal $\mathrm{CO} 2$ change during the hypercapnia manipulation for each participant to yield CBF-CVR. The baseline CBF was then used to compute absolute values of CBF-CVR.

\subsection{Vascular lesion quantification}

White matter hyperintensity volume (WMH) for the whole brain was quantified semi-automatically. As previously described (Gauthier et al. 2015; Intzandt et al. 2019) visual identification on FLAIR images were completed by a single rater who was blinded to clinical 
information, which were then delineated using the Jim image analysis package, version 6.0 (Xinapse Systems Ltd, Northants, UK). WMH volume for the whole brain was quantified using tools from the FMRIB Software Library (FSL).

\subsection{Pulse Wave Velocity Data}

The aortic data was analyzed using the ARTFUN software (Herment et al. 2010), where pulse wave velocity in the aortic arch was computed between the ascending and descending aorta from cine phase contrast images. The aortic lumen contours of the ascending and descending aorta were automatically segmented using amplitude images of cine phase contrast series where flow profiles were also estimated. PWV was calculated as described in (Gauthier et al. 2015; Intzandt et al. 2019).

\subsection{Blood Tests}

Before the MRI exam, participants underwent a blood draw. The blood samples were used to test the concentration of hemoglobin and hematocrit (Gauthier et al. 2015).

\subsection{Statistical Analysis}

Statistical analysis of all data was done using IBM SPSS Statistics for Windows, Version 24.0 (IBM Corp., Armonk, NY). Descriptive statistics for age, education, MMSE scores, WMH, CBF-CVR, PWV and executive functioning scores are reported in the whole sample and compared between males and females in Table 1. Statistical comparisons between males and females were done using independent samples $t$-tests. Moderation analyses were performed using the PROCESS Macro for moderation analyses (Hayes 2017). The analyses were bootstrapped to amend any shortcoming in power by simulating greater data based on an algorithm to maintain the current pattern. By default, bootstrapped samples were set to simulate 5,000 samples (Hayes 2017). Moderation effects of sex on the PWV-CVR, PWV-EF, and CVR-EF relations were tested controlling for age and WMH volume. In addition, a moderated moderation analysis was conducted to see if the sex effects in the moderations could be explained by differences in hemoglobin (Fig. 7, Fig. 8).

\subsection{Data and code availability}

The preprocessing scripts along with scripts used to analyze data can be made available upon reasonable request. Research data is available upon request.

\section{Results}

A total of 48 older adults (31 females, 17 males) were included in the analysis. Participant characteristics are summarized in Table 1. It was found that females had a significantly higher resting CBF $(p<0.05)$ in whole brain grey matter, higher composite scores for executive functioning $(p<0.05)$ and lower hemoglobin and hematocrit than males $(p<0.05)$. There was no 
difference between males and females for PWV $(p>0.05)$ and CBF-CVR $(p>0.05)$ in whole brain grey matter.

Table 1: Participant Demographics.

\begin{tabular}{|l|l|l|l|}
\hline Demographic & All $(\mathbf{n}=\mathbf{4 8})$ & Males $(\mathbf{n}=\mathbf{1 7})$ & Females $(\mathbf{n}=\mathbf{3 1})$ \\
\hline Age (years) & $63.35 \pm 4.86$ & $64 \pm 4.37$ & $63 \pm 5.14$ \\
\hline Education (years) & $16.29 \pm 3.56$ & $16.18 \pm 3.32$ & $16.3 \pm 53.74$ \\
\hline $\begin{array}{l}\text { EF* } \\
\text { (composite score) }\end{array}$ & $0.003 \pm 0.74$ & $-0.31 \pm 0.87 *$ & $0.177 \pm 0.60 *$ \\
\hline PWV (m/s) & $8.70 \pm 2.89$ & $8.89 \pm 2.99$ & $8.59 \pm 2.88$ \\
\hline MMSE (out of 30) & $28.79 \pm 0.94$ & $28.53 \pm 1.32$ & $28.94 \pm 0.63$ \\
\hline \begin{tabular}{l} 
Log WMH volume \\
\hline Resting CBF (ml/100g/min)*
\end{tabular} & $42.46 \pm 10.05$ & $35.74 \pm 8.71 *$ & $46.14 \pm 8.85 *$ \\
\hline $\begin{array}{l}\text { CBF-CVR } \\
(\mathrm{ml} / 100 \mathrm{~g} / \mathrm{min} / \mathrm{mmHg} \text { CO2 })\end{array}$ & $4.64 \pm 2.39$ & $4.50 \pm 2.52$ & $0.35 \pm 0.17$ \\
\hline HBG (g/L)* & $139.49 \pm 11.27$ & $148.41 \pm 11.24 *$ & $134.45 \pm 7.77 *$ \\
\hline HCT * & $0.421 \pm 0.03$ & $0.447 \pm 0.321^{*}$ & $0.406 \pm 0.241 *$ \\
\hline
\end{tabular}

$* \mathrm{p}<0.05$

\subsection{Moderation Analysis}

Our results revealed a significant standardized direct effect of PWV on CVR $(\beta=1.6307, \mathrm{SE}=$ $0.4839,95 \%$ CI $[0.654,2.607], \mathrm{p}=0.0016)$ as depicted in Figure 1 . The moderation effect (SEX $* \mathrm{PWV})$ was also a significant predictor of CVR $(\beta=-1.013, \mathrm{SE}=0.2957,95 \% \mathrm{CI}[-1.610$, -0.4169], $p=0.0014$ ) showing that the effect of PWV on CVR was a function of sex. Further analysis revealed that the effect of PWV on CVR was significantly positive in males $(\beta=0.6170$, $\mathrm{SE}=0.2184,95 \% \mathrm{CI}[0.1762,1.0577], \mathrm{p}=0.0072)$ and significantly negative in females $(\beta=$ $-0.3967, \mathrm{SE}=0.1902,95 \% \mathrm{CI}[-0.7805,-0.0129], \mathrm{p}=0.0431)$ (see Figure 2). 
Int_1 $\beta=-1.0137 \pm \mathrm{se}=0.2957, \mathrm{p}=0.0014$

Males $\beta=0.6170 \pm \mathrm{se}=0.2184, \mathrm{p}=0.0072$

Females $\beta=-0.3967 \pm \mathrm{se}=0.1902, \mathrm{p}=0.0431$

\section{SEX}

PWV

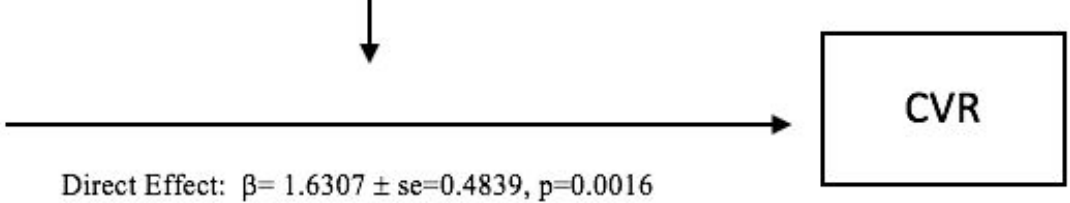

Figure 1: Moderation Effect (PWV*SEX) on CVR

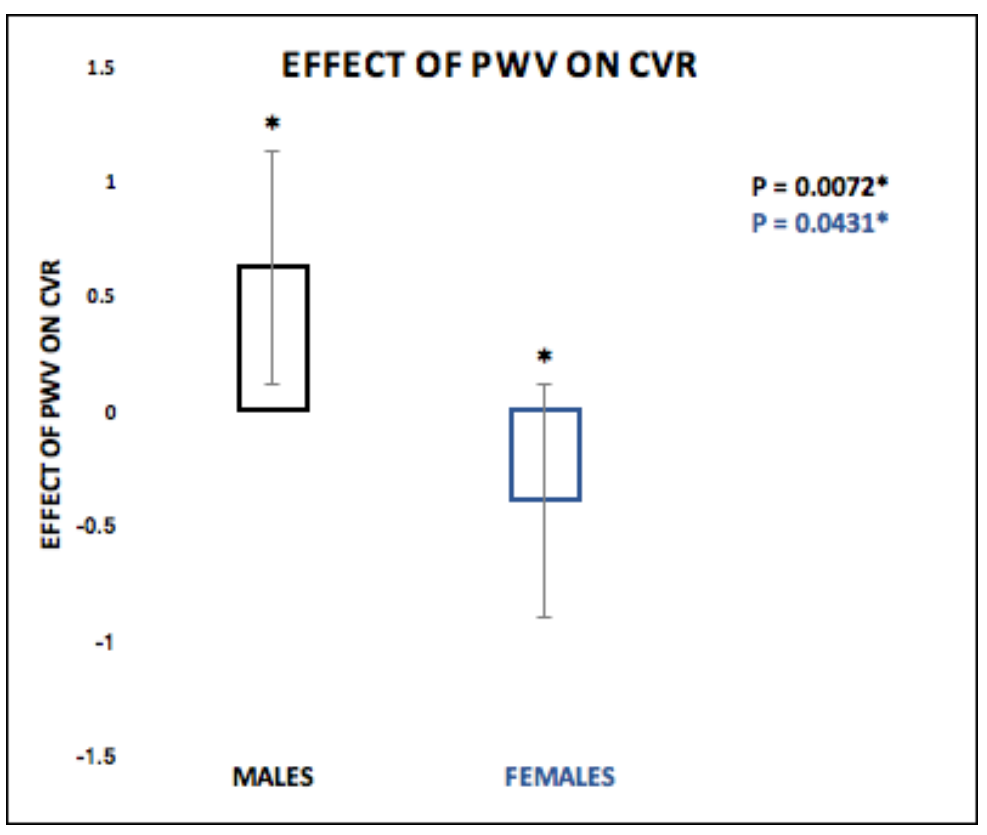

\section{Figure 2: Effect of PWV on CVR}

CVR was significantly positive in males $(p=0.0072) *$ and significantly negative in females $(p=0.0431) *$.

Our results also revealed a significant standardized direct effect of PWV on EF ( $\beta=-0.9980$, SE $=0.3463,95 \%$ CI $[-1.6970,-0.2990], p=0.0062)$. The moderation effect (SEX *PWV) was also a significant predictor of $\mathrm{EF}(\beta=0.4479, \mathrm{SE}=0.2117,95 \% \mathrm{CI}[0.0207,0.8751], \mathrm{p}=0.0403)$ showing that the effect of PWV on EF was a function of sex (Figure 3). As shown in Figure 4 the effect of PWV on EF was significantly negative in males $(\beta=-0.5501, \mathrm{SE}=0.1563,95 \% \mathrm{CI}$ $[-0.8656,-0.2346], p=0.0011)$ but not significant in females $(\beta=-0.1022, \mathrm{SE}=0.1361,95 \% \mathrm{CI}$ $[-0.3769,0.1725], \mathrm{p}=0.4569)$. 
Int_1 $\beta=0.4479 \pm \mathrm{se}=0.2117, \mathrm{p}=0.0403$

Males $\beta=-0.5501 \pm \mathrm{se}=0.1563, \mathrm{p}=0.0011$

Females $\beta=-0.1022 \pm \mathrm{se}=0.1361, \mathrm{p}=0.4569$

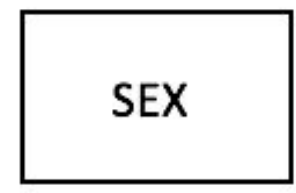

SEX

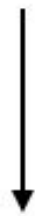

\section{PWV}

Direct Effect: $\beta=-0.9980 \pm \mathrm{se}=0.3463, \mathrm{p}=0.0062$

Figure 3: Moderation Effect (PWV*SEX) on EF

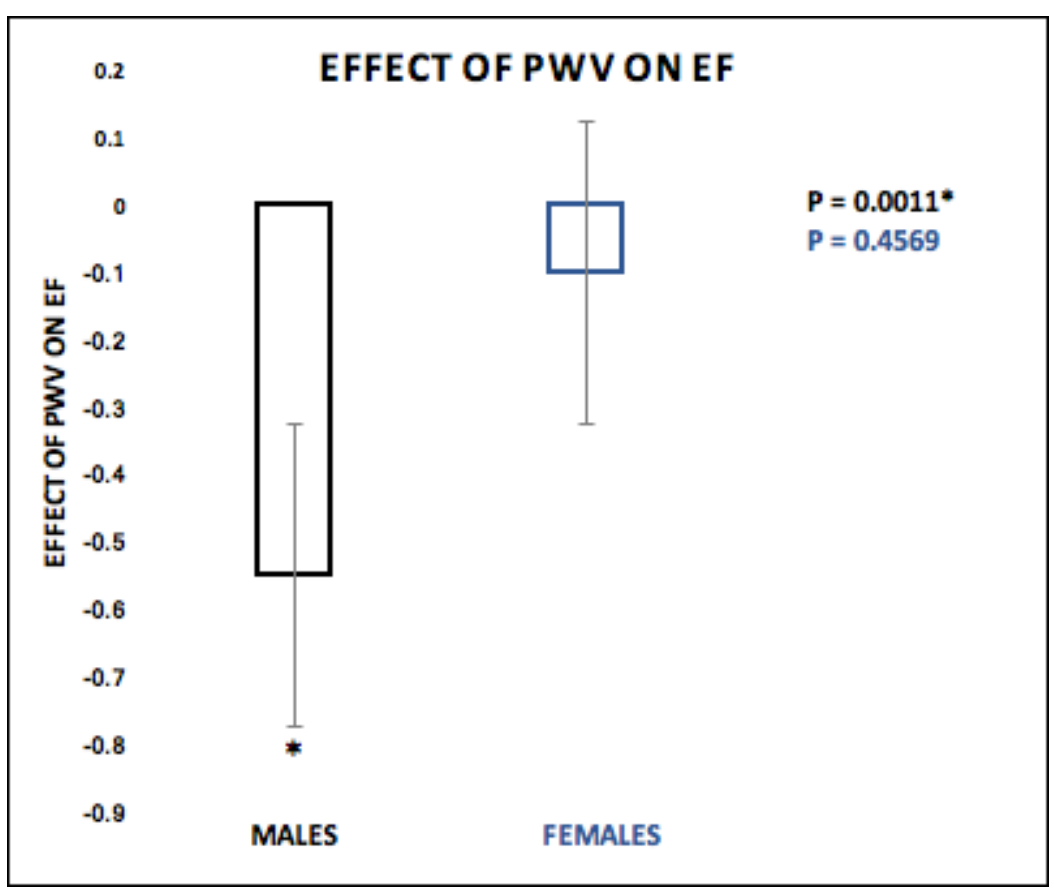

Figure 4: Effect of PWV on EF

The effect of $P W V$ on $E F$ was significant negative in males $(\beta=-0.5501, S E=0.1563,95 \% C I$ $[-0.8656,-0.2346], p=0.0011)$ but not significant in females $(\beta=-0.1022, S E=0.1361,95 \% C I$ [-0.3769, 0.1725], $p=0.4569)$.

Finally, a moderation analysis also revealed a significant standardized direct effect of CVR on $\mathrm{EF}(\beta=-0.8472, \mathrm{SE}=0.3332,95 \% \mathrm{CI}[-1.5195,-0.1748], \mathrm{p}=0.0148)$. However, the moderation effect $(\mathrm{SEX} * \mathrm{CVR})$ did not predict EF $(\beta=0.3438, \mathrm{SE}=0.1990,95 \%$ CI $[-0.0579,0.7455], \mathrm{p}=$ 
0.0914) (Figure 5).

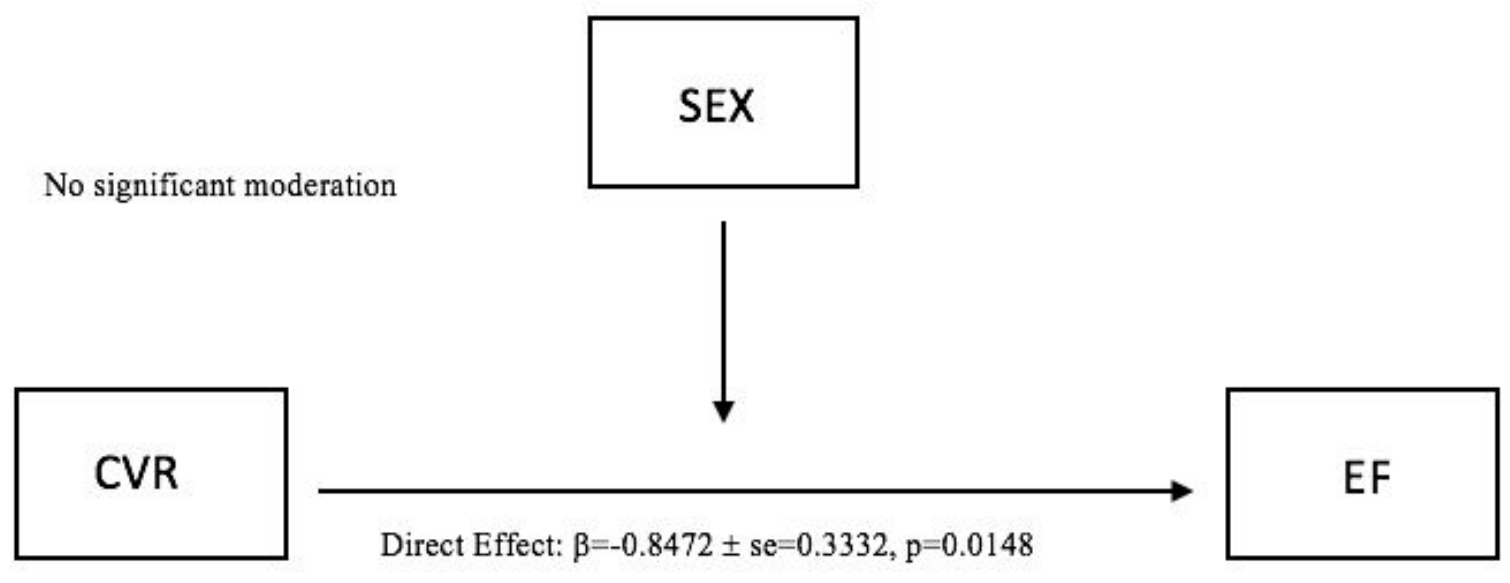

Figure 5: Moderation model (CVR*SEX) on EF

\subsection{Moderated Moderation Analysis}

A moderated moderation analysis was conducted to determine if the sex effects in our moderation could be explained by differences in, given the sex differences in hematocrit concentration shown in Table 1.We found that there was no effect of HCT on the sex differences observed in the moderation effect (PWV*SEX) on CVR (Figure 6).

No significant moderated moderation
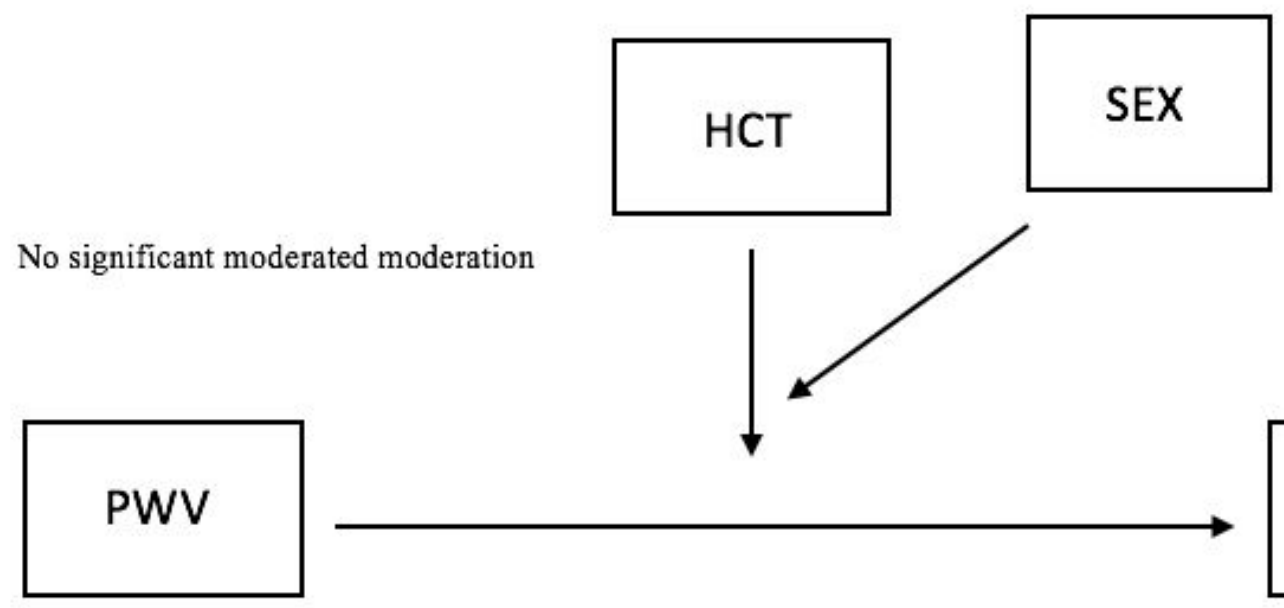

ted moderation


Figure 6: Moderated moderation model depicting the effect of HCT on the relationship PWV on CVR among sexes

In addition, through a moderated moderation analysis we tested whether sex moderated the moderation effect of HCT on the relationship between PWV and EF. It was found that the moderated moderation effect ( $\mathrm{PWV} * \mathrm{HCT} * \mathrm{SEX})$ was a significant predictor of $\mathrm{EF}(\beta=0.5554$, $\mathrm{SE}=0.2500,95 \%$ CI $[.0492,1.0615], \mathrm{p}=0.0324)$ (Figure 7). As shown in Figure 8 the effect of PWV on EF was negative in males $(\beta=-0.3097, \mathrm{SE}=0.4479,95 \%$ CI [-1.2164, 0.5970], $\mathrm{p}=0.4934)$ and significantly negative in females $(\beta=-0.4797, \mathrm{SE}=0.1985,95 \%$ CI $[-0.8815$, -0.0779], $\mathrm{p}=0.0206)$ with low HCT levels $(0.3884 \mathrm{~g} / \mathrm{L})$. In addition, the effect of PWV on EF was negative for both males $(\beta=-0.4394, \mathrm{SE}=0.2936,95 \% \mathrm{CI}[-1.0338,0.1549], \mathrm{p}=0.1427)$ and females $(\beta=-0.0834, \mathrm{SE}=0.1273,95 \%$ CI $[-0.3411,0.1742], \mathrm{p}=0.5161)$ with medium HCT levels $(0.4200 \mathrm{~g} / \mathrm{L})$ but did not reach significance. Lastly, it was found that the effect of PWV on EF was significantly negative for males $(\beta=-0.5626, \mathrm{SE}=0.1774,95 \% \mathrm{CI}[-0.9216,-0.2035]$, $\mathrm{p}=0.0030)$ and positive for females $(\beta=0.2928, \mathrm{SE}=0.2042,95 \% \mathrm{CI}[-0.1207,0.7063]$, $\mathrm{p}=0.1599)$ with high HCT levels $(0.4500 \mathrm{~g} / \mathrm{L})$.

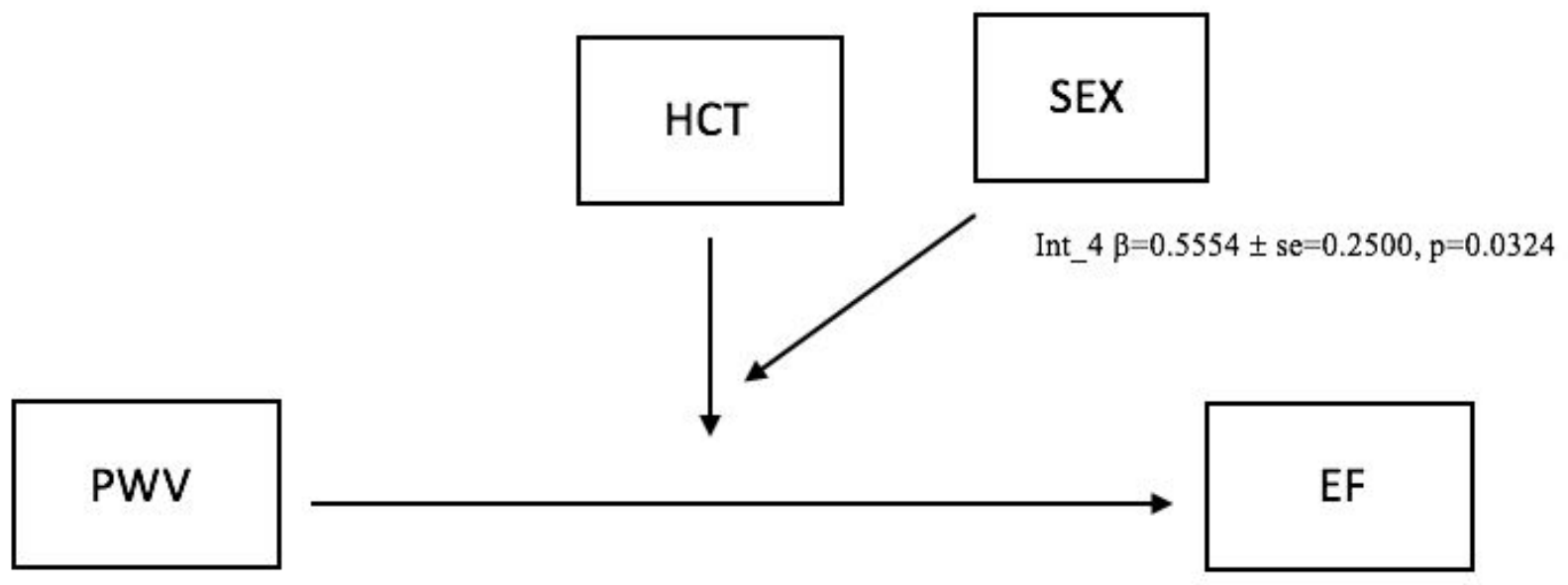

Figure 7: Moderated moderation model depicting the effect of HCT on the relationship PWV on EF among sexes 


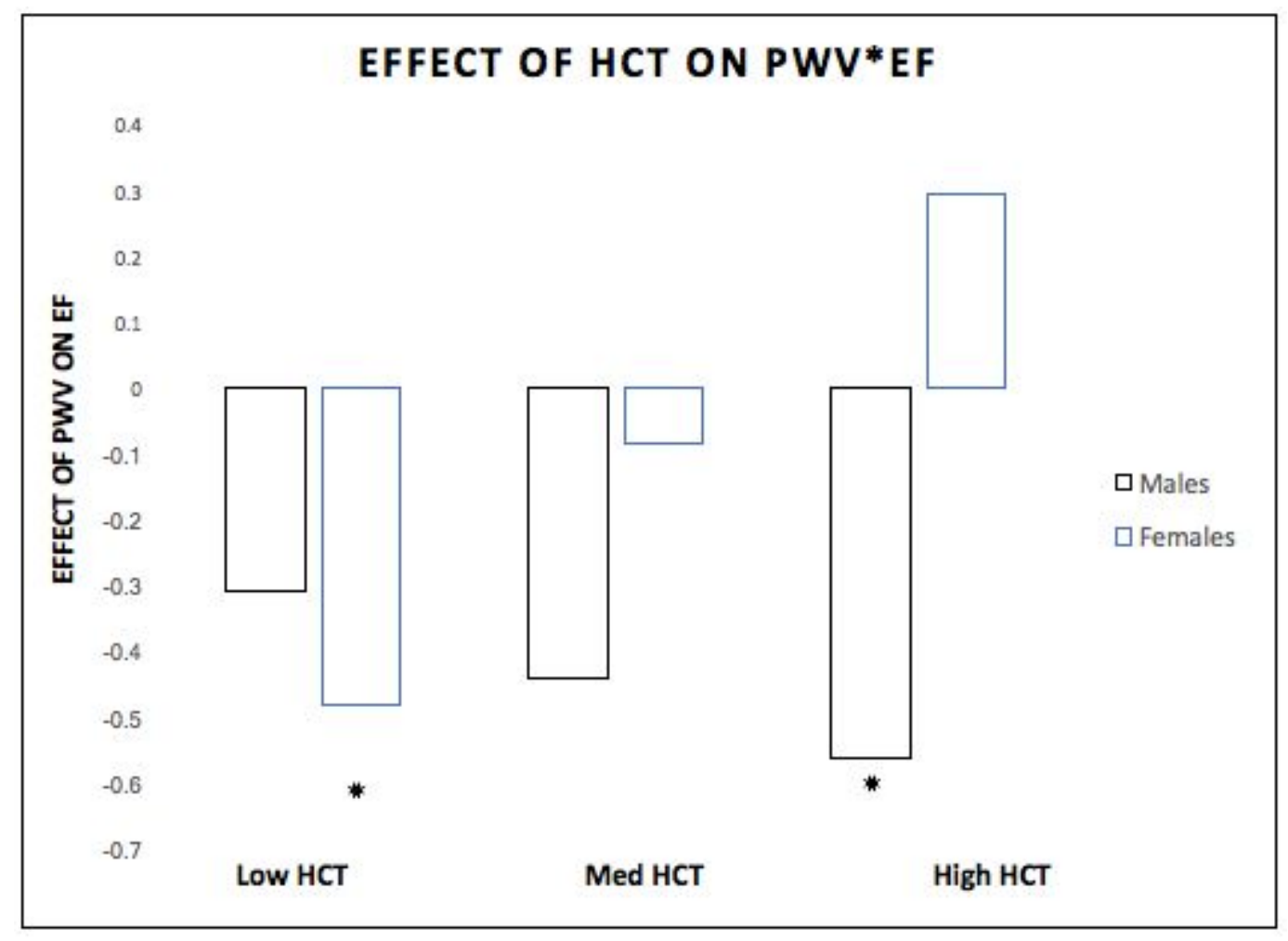

Figure 8: The effect of HCT on the relationship PWV on EF among sexes. The effect of PWV on EF was significantly negative $(p=0.0206) *$ in females (blue) with low HCT levels and significantly negative $(p=0.0030) *$ in males (black) with high HCT levels.

\section{Discussion}

\subsection{Main Results}

In this study, we investigated the impact of sex on the link between PWV, cognitive performance and CVR. An important finding is that sex moderates the relationship between: i) PWV and CVR; and ii) PWV and EF; but not between iii) CVR and EF. Specifically, the effect of PWV on CVR was significantly positive in males and significantly negative in females. Additionally, the effect of PWV on EF was significantly negative in males but not significant in females. Furthermore, results from the moderated moderation analysis revealed that there was no effect of HCT on the sex differences observed in the moderation effect of sex on the relationship between PWV and CVR, however there was a significant effect of HCT on the sex differences observed in the moderation effect of sex on the relationship between PWV and EF. Together, our results indicate that some of the complex relationships between PWV, CVR and EF shown in the literature are being driven by sex and that HCT may be involved in driving some of these sex effects. 


\subsection{Sex Differences}

The sex differences identified in this study are consistent with the existing literature, including differences in $\mathrm{CBF}, \mathrm{HCT}$ and $\mathrm{EF}$ performance. In this sample, females have higher resting CBF than males. These findings are similar to previous studies with healthy older adults indicating that females typically display greater resting global CBF (Rodriguez et al. 1988; Esposito et al. 1996) and higher CBF velocities compared to males (Vriens et al. 1989; Martin et al. 1994; Oláh et al. 2000; Tegeler et al. 2013). In addition, several studies have reported data suggesting that males and females tend to present with different levels of performance in certain cognitive domains (Burstein et al. 1980; Kennison 2003; Castonguay et al. 2015). Indeed, our findings of decreased executive function scores in older males compared to older females are also in line with previous research (Halpern and LaMay 2000). Finally, in our population, females had significantly lower hemoglobin levels than males, consistent with previous findings showing that females have mean levels of approximately $12 \%$ lower than males (Murphy 2014).

\subsection{Arterial stiffness and cerebrovascular reactivity}

Overall, there is substantial evidence supporting an effect of sex hormone on vascular stiffness (Ogola et al. 2018; DuPont et al. 2019). Over the lifespan, arterial stiffness increases linearly in both males and females however there is a more rapid increase in stiffness in females due to depletions in estrogen levels post menopause (Mitchell 2014; DuPont et al. 2019). Indeed, several studies have shown that hormone receptors, including estrogen and testosterone are cardio-protective (DuPont et al. 2019; Wu et al. 2014; Karas et al. 1994; Dockery et al. 2003). Previous work highlighting the protective effects of estrogen have shown that arterial stiffness, measured using cfPWV, is reduced in postmenopausal females taking hormone replacement therapy (HRT) when compared to matched females not taking HRT (Rajkumar et al. 1997; DuPont et al. 2019). In addition, testosterone was once perceived to play a role in promoting CVD among males (Thompson et al. 1989; Sullivan et al. 1998), however recent epidemiological studies point to the contrary. Testosterone deficiency has been associated with increased cfPWV among healthy older males compared to age-matched males (Vlachopoulos et al. 2014; DuPont et al. 2019). In addition, low testosterone has also been associated with impaired microvascular function and arterial elasticity, measured using the augmentation index. (Corrigan et al. 2015; DuPont et al. 2019). Finally, it is known that testosterone can be converted to estrogen in the brain, so that the protective effects of estrogen may in fact be more preserved in older males than females (Robison et al. 2019). Overall, ample data suggest that sex hormones substantially impact the manifestation of arterial stiffness among males and females. As such, a thorough understanding of the underlying mechanisms that contribute to these sex differences could aid in developing sex-specific strategies to reduce or prevent CVD risk.

Although quantitative measurements of CBF and CVR in relation with arterial stiffness have been performed by others (DuBose et al. 2018; Jefferson et al. 2018), the literature shows conflicting results. While more recent reports suggest a preserved CVR with increased aortic stiffness (Jefferson et al. 2018; Zhu et al. 2013), earlier studies using PET and TCD rather than MRI did not find such an association, but rather reductions in CVR among adults with greater aortic stiffness (DuBose et al. 2018; Jaruchart et al. 2016). It is possible however that these 
counterintuitive findings could stem from differences in study designs, heterogeneity of target populations (males vs females) and/or differences in imaging modalities. For example, one previous TCD study describing sex-related differences in cerebral vasomotor reactivity has shown increased vasodilatory response in females compared with male subjects (Matteis et al. 1998). More importantly, these studies did not control for menstrual phase or account for sex hormones, which are known to acutely alter CBF and cerebrovascular responsiveness (Brackley et al. 1999; Krejza et al. 2001; Krejza et al. 2003; Krejza et al. 2013; Nevo et al. 2007).

Following these and our results, it is imperative that different models should be created for sex rather than just regressing out the effects of sex.

Our work presents the first evidence of a sex moderation in the relationship between PWV and CVR. Our findings of low CVR among females and high CVR among males with increased arterial stiffness are in line with the contradictory results found in the extant literature, with females following the trend observed by DuBose et al and Jaruchart et al. (DuBose et al. 2018; Jaruchart et al. 2016) and male data being in agreement with the results of Jefferson et al. (Jefferson et al. 2018). The biological underpinnings of these differences may be of several origins and as yet there is little data to support a particular hypothesis. However, it could be differential remodeling or damage as a function of stiffness may depend on the time course of stiffness (with men having a potentially more protracted time course since they do not undergo menopause), or may be due to different biases in the CVR technique in males and females. ASL is highly dependent on transit time of the tag for example, and differences in velocity and transit time could for example explain some of these effects. More studies investigating potential sex-dependent methodological biases, and the biological changes that underpin vascular changes in aging in both sexes are needed to start addressing this question.

\subsection{The association between pulse wave velocity and cognitive function relative to sex}

In the present study the relationship between arterial stiffness and EF was in part driven by differences in sex. We also demonstrate that higher arterial stiffness, as measured by PWV, is associated with poorer performance on EF tasks among males only. Our findings are in line with prior studies that have demonstrated sex differences in the relationship between arterial stiffness and cognitive function. For instance, Singer et al. found no significant association between arterial stiffness and global cognition, however negative associations between PWV and composite global cognition were observed in males only when stratifying the sample by sex (Singer et al. 2013). Similarly, Waldstein et al reported males as scoring significantly lower than females on tests of verbal memory at higher levels of pulse pressure, an alternative measure of arterial stiffness (Waldstein et al. 2008). In addition, there is good agreement in the literature showing that arterial stiffness and related central hemodynamics are associated with reductions in cognitive performance on memory, processing speed, and executive function tasks (Iulita et al. 2018; Singer et al. 2014; Badji et al. 2019). However, these studies are limited because they have used a nonspecific measure of cognition (i.e MMSE). Here, we extend their findings to include executive function domains that are especially susceptible to cardiovascular disease (Gorelick et al. 2012). Indeed, our results are consistent with other studies pointing to a general association between PWV and executive dysfunction (Lim et al. 2016; Poels et al. 2007; Hajjar et al. 2016). For example, Hajjar et al found that subjects with higher PWV had the greatest 4-year risk of decline in executive function (Hajjar et al. 2016). It has been hypothesized that this may be due to the fact that the 
dorsolateral prefrontal cortex, essential for executive function tasks, is situated in a watershed region of the brain (Suchy 2015; de la Torre 2002). Thus, one could speculate that with increased arterial stiffness, these regions may be deprived of perfusion and therefore oxygen earlier than better perfused regions (Suchy 2015; de la Torre 2002).

Our results showed no significant association between arterial stiffness and EF among females. Moreover, females in this cohort displayed significantly better performance than males on the cognitive tasks assessed. It is well known that there are significant differences between sexes in regards to vascular function and cognitive performance among older adults (Castonguay et al. 2015; Narkiewicz et al. 2006). Indeed, across the lifespan, males have a higher risk for CVDs and females are relatively protected until menopause after which they catch up to males, likely due to estrogen depletion (Singer et al. 2013; Narkiewicz et al. 2006). In addition, males have a higher prevalence of mild cognitive impairment compared to females (Petersen et al. 2010; Brodaty et al. 2013; Singer et al. 2013). A possible hypothesis for these sex differences is that males experience cognitive decline earlier in life, while females transition from normal cognition to impaired cognition in the decades following menopause (Petersen et al. 2010).

\subsection{The association between cognitive function and cerebrovascular reactivity relative to sex}

While the vessel reactivity-cognition link has been investigated in cardiovascular and neurodegenerative disorders, the association between CVR and cognition in healthy aging is unclear. Most reports indicate that blood vessel reactivity in the brain decreases with healthy aging (Reich and Rusinek 1989; Lu et al. 2011; Gauthier et al. 2015; Gauthier et al. 2013; Gauthier et al. 2012; Bhogal et al. 2016; De Vis et al. 2015). The mechanisms underlying this decreasing reactivity of cerebral vessels with aging are postulated to be related to local vascular stiffening (Desjardins 2015). An interesting finding of our study is that sex did not moderate the relationship between CVR and EF among older adults, suggesting that other hemodynamics mechanisms may be at play. Interestingly, recent work published by our group has shown that CVR, which could be interpreted as an indirect measure of vascular elasticity in the brain, may not be uniquely dependent on brain-based vascular properties and may be partly dependent on more global properties such as changes in endothelial function, chemosensitivity and cerebral autoregulation (Intzandt et al. 2019). Indeed, the lack of moderation between CVR and cognition could be attributable to the fact that this indirect measure of stiffness in the brain may be biased by unknown physiological changes and may underestimate the effects of arterial stiffness on cerebral hemodynamics. As such, CVR should be interpreted with caution as a surrogate measure of stiffness in the brain. Nonetheless, future work aiming to disentangle the relationships between CVR and cognition should implement more robust and direct measures of vascular elasticity in the brain (Baraghis et al. 2011; Warnert et al. 2016).

\subsection{The Effect of Hematocrit}

Additionally, we aimed to assess if the sex effects observed in the moderation effect (PWV*SEX) on EF were driven by differences in hematocrit. Our findings suggest that HCT may be in part driving these sex differences. Interestingly, it has previously been shown that males and females have different levels of hemoglobin which affect MR measures of flow (Kimberly et al. 2013; Yip et al. 1984; 
Vahlquist and Others 1950; Garn et al. 1975). Since PWV, a surrogate marker for stiffness, is dependent on the differences in pressure which in turn is dependent on radius of vessels and blood viscosity, it is plausible that our results partly reflect a blood viscosity effect (Stojadinović et al. 2015; Painter 2008). We reasoned that PWV as a measure of stiffness may not be pure. Interestingly, most published studies have ignored the effect of blood viscosity on PWV measurement, since the measure is based on the underlying assumption that blood viscosity is constant across subjects (Stojadinović et al. 2015; Parkhurst et al. 2012). It has been previously shown that there might be some relation between blood flow and vascular wall, and that blood viscosity as a mechanical property of blood flow might affect measures of PWV (Kim et al. 2013).

\section{7 Limitations}

The results from this study should be viewed in light of some limitations. First, menopausal status and hormonal levels were not acquired at the time of the study. It is assumed that our female population is predominantly postmenopausal given that the age range was 55-75 years, with a mean age of 63 . In fact, the average age of naturally-occurring menopause in Canada is 51 years (Canadian consensus conference on menopause, 2006). Nonetheless, this assumption is speculative, and other studies should account for menopausal status to replicate and provide clarity on the mechanisms that underlie the present results. Future work should include younger subjects (40-55 years of age) to better study hormonal status in females.

While a strength of the current study is the use of non-invasive quantitative perfusion imaging to calculate cerebral blood flow and CVR, one must note that the ASL technique suffers from several limitations. The contrast afforded by the subtraction of tagged images is only a fraction of a percent of the functional MRI contrast, providing limited signal-to-noise ratio (SNR) (Golay and Petersen 2006; Badji et al. 2019). Furthermore, full coverage of the brain is typically not possible without advanced multi-band approaches, limiting the ability to draw conclusions on the entire brain (Badji et al. 2019; Golay and Petersen 2006). Finally, most ASL imaging methods are unable to determine whether the changes detected are true reflections of changes in flow or the result of alterations in transit times (Badji et al. 2019). This is especially problematic in the case of single delay ASL studies, such as the one presented here. Despite these limitations of ASL, it has consistently been shown that CBF-CVR is a more specific measure of vascular health than BOLD-CVR (Halani et al. 2015). Indeed, BOLD is more sensitive to vascular elasticity than $\mathrm{CBF}$, and may be the best choice when sensitivity is desired over specificity (Halani et al. 2015). In addition to the general limitations of ASL, the post-labeling delay chosen in this study is suboptimal for older adults since it was optimized for a younger population (Badji et al. 2019; Intzandt et al. 2019). As such, with our limited SNR, it is possible that our CBF data before and during hypercapnia was underestimated. Thus, to better understand the relationship between arterial stiffness, cognition and CVR, longitudinal studies using multi-band approaches and multi-delay implementations with optimized post-labeling delays are necessary.

Another limitation to this study is our sample size. Indeed, our subset of female and male participants is small, limiting our ability to fully generalize our findings to the general population. Indeed, it may be plausible that due to our small sample size we were unable to detect the mediating effect of sex in some of our models. In addition, our ratio of males $(n=17)$ to females $(n=31)$ in this sample may be biased toward females, underrepresenting our male population. As such, our study may lack adequate statistical power to detect an effect size of practical importance, especially in males. Nonetheless, our 
analyses were bootstrapped which can overcome the power problem of small samples. Also, our sample included predominantly very healthy older adults, limiting our ability to generalize our findings to other older adults, who often suffer from cardiovascular risk factors. We speculate that associations reported here would likely be stronger in a cohort with worse cardiovascular health. Moreover, a follow-up study with better statistical power is needed to confirm our findings.

Finally, this study has a cross sectional design making it difficult to draw general conclusions on the population. Although this study provides valuable knowledge on the impact of sex on the relationship between aortic stiffness, cognition an CVR, a longitudinal study is needed to better understand the sex differences among those hemodynamic measures across the lifespan to better personalize CVD prevention strategies.

\section{Conclusion}

The findings from this study add to a growing body of research that underscores the interrelationship between cardiovascular function and brain health among aging adults. Overall, this paper identified a sex moderation between PWV and CVR, PWV and EF but not between CVR and EF in a sample of healthy older adults. Our data also demonstrated that HCT may play a role in driving some of these sex effects. These findings could be the results of different sex hormones, such as estrogen and testosterone, that are known to alter cerebrovascular measures of brain health. Finally, as the key oxygen-carrying molecule in the body, hemoglobin may play a direct role in influencing vascular measures of stiffness such as PWV and affect MR measures of flow. More importantly, understanding these hemodynamic associations may lead to earlier detection and targeted interventions to prevent or lessen the onset of cardiovascular diseases linked with higher aortic stiffening. Thus, future longitudinal studies that explore sex differences should include evaluation of the role of hemoglobin and investigate the role of hormone variations (i.e. sex hormones).

\section{Declaration of interest}

The first author Dalia Sabra has an affiliation with the following institutions: Universite de Montreal, Department of Biomedical Science, Faculty of Medicine, Montreal, QC, Canada; Research Center, Montreal Heart Institute, Montreal, QC, Canada; Centre de recherche de l'Institut Universitaire de Geriatrie de Montreal, Montreal, QC, Canada; Department of Medicine, Universite de Montreal, Montreal, QC, Canada. The author Brittany Intzandt has an affiliation with the Montreal Heart Institute, Montreal, QC, Canada; Centre de recherche de l'Institut Universitaire de Geriatrie de Montreal, Montreal, QC, Canada; PERFORM centre, Concordia University, Montreal, QC, Canada; INDI Department, Concordia University, Montreal, QC, Canada. The author Laurence Desjardins- Crepeau has an affiliation with the Montreal Heart Institute, Montreal, QC, Canada and the centre de recherche de l'Institut Universitaire de Geriatrie de Montreal, Montreal, QC, Canada. The author Antoine Langeard has an affiliation with the Montreal Heart Institute, Montreal, QC, Canada; Centre de recherche de l'Institut Universitaire de Geriatrie de Montreal, Montreal, QC, Canada; LITO laboratory, Inserm, Institut Curie, Orsay, France. The author Christopher J. Steele has an affiliation with the 
Concordia University, Department of Psychology, Montreal, QC, Canada; Department of Neurology, Max Planck Institute for Human Cognitive and Brain Sciences, Leipzig, Germany; PERFORM Centre, Concordia University, Montreal, QC, Canada. The author Frédérique Frouin has an affiliation with LITO laboratory, Inserm, Institut Curie, Orsay, France. The author Richard D. Hoge has an affiliation with the Montreal Neurological Institute, Montreal, QC, Canada and the Department of Neurology and Neurosurgery, McGIll University, Montreal, QC, Canada. The author Louis Bherer has an affiliation with the Research Center, Montreal Heart Institute, Montreal, QC, Canada; Centre de recherche de l'Institut Universitaire de Geriatrie de Montreal, Montreal, QC, Canada; Department of Medicine, Universite de Montreal, Montreal, QC, Canada. The corresponding author Claudine J. Gauthier has an affiliation with the Montreal Heart Institute, Montreal, QC, Canada; Department of Physics, Concordia University, Montreal, QC, Canada and the PERFORM Centre, Concordia University, Montreal, QC, Canada.

\section{Acknowledgements}

The authors thank Carollyn Hurst and André Cyr for their help with data acquisition, Élie Mousseaux, Alban Redheuil, Muriel Lefort, Frédérique Frouin, and Alain Herment for their help with the aortic protocol and analysis, Cécile Madjar, Mélanie Renaud and Élodie Boudes for their help with logistics, and Catherine Foster for helpful discussions. The authors thank Ellen Garde, Arnold Skimminge and Pernille Iversen for their help with vascular lesion segmentation. They thank Céline Denicourt for performing the blood draws. They thank Jiongjiong Wang of the Department of Neurology at UCLA who provided the dual-echo pseudo-continuous arterial spin labeling sequence. This work was supported by the Canadian Institutes of Health Research (MOP 84378, Banting and Best Scholarship held by C.J. Gauthier), the Canada Foundation for Innovation (Leaders Opportunity Fund 17380), the Ministère du développement économique, de l'innovation et de l'exportation (PSR-SIIRI-239), the Canadian National Sciences and Engineering Research Council (R0018142, RGPIN 2015-04665), the Heart and Stroke Foundation of Canada (New Investigator Award held by C.J. Gauthier), and the Michal and Renata Hornstein Chair in Cardiovascular Imaging (Montreal Heart Institute, held by C.J.G.).

\section{References}

Adams, M. R., Kaplan, J. R., Koritnik, D. R., \& Clarkson, T. B. (1987). Pregnancy-associated inhibition of coronary artery atherosclerosis in monkeys. Evidence of a relationship with endogenous estrogen. Arteriosclerosis , 7(4), 378-384.

Ahnstedt, H., Cao, L., Krause, D. N., Warfvinge, K., Säveland, H., Nilsson, O. G., \& Edvinsson, L. (2013). Male-female differences in upregulation of vasoconstrictor responses in human cerebral arteries. PloS One, 8(4), e62698. 
Allen, J. S., Bruss, J., Brown, C. K., \& Damasio, H. (2005). Normal neuroanatomical variation due to age: the major lobes and a parcellation of the temporal region. Neurobiology of Aging, 26(9), 1245-1260; discussion 1279-1282.

Alsop, D. C., Detre, J. A., Golay, X., Günther, M., Hendrikse, J., Hernandez-Garcia, L., ... Zaharchuk, G. (2015). Recommended implementation of arterial spin-labeled perfusion MRI for clinical applications: A consensus of the ISMRM perfusion study group and the European consortium for ASL in dementia. Magnetic Resonance in Medicine: Official Journal of the Society of Magnetic Resonance in Medicine / Society of Magnetic Resonance in Medicine, 73(1), $102-116$.

Appelros, P., Stegmayr, B., \& Terént, A. (2009). Sex differences in stroke epidemiology: a systematic review. Stroke; a Journal of Cerebral Circulation, 40(4), 1082-1090.

Ashburner, J., \& Friston, K. J. (2000). Voxel-Based Morphometry-The Methods. NeuroImage, $11(6), 805-821$.

Avants, B. B., Epstein, C. L., Grossman, M., \& Gee, J. C. (2008). Symmetric diffeomorphic image registration with cross-correlation: evaluating automated labeling of elderly and neurodegenerative brain. Medical Image Analysis, 12(1), 26-41.

Badji, A., de la Colina, A. N., Sabra, D., Karakuzu, A., Bherer, L., Lamarre-cliche, M., ... Girouard, H. (2019). The relationship between cognitive function, cortical blood flow and sub-cortical white-matter health in the elderly. JOURNAL OF CEREBRAL BLOOD FLOW AND METABOLISM, 39, 29-30. SAGE PUBLICATIONS INC 2455 TELLER RD, THOUSAND OAKS, CA 91320 USA.

Badji, A., Sabra, D., Bherer, L., Cohen-Adad, J., Girouard, H., \& Gauthier, C. J. (2019). Arterial Stiffness and Brain Integrity: A review of MRI findings. Ageing Research Reviews. https://doi.org/10.1016/j.arr.2019.05.001

Baraghis, E., Bolduc, V., Lefebvre, J., Srinivasan, V. J., Boudoux, C., Thorin, E., \& Lesage, F. (2011). Measurement of cerebral microvascular compliance in a model of atherosclerosis with optical coherence tomography. Biomedical Optics Express, 2(11), 3079-3093.

Benetos, A., Watfa, G., Hanon, O., Salvi, P., Fantin, F., Toulza, O., ... PARTAGE Study Investigators. (2012). Pulse wave velocity is associated with 1-year cognitive decline in the elderly older than 80 years: the PARTAGE study. Journal of the American Medical Directors Association, 13(3), 239-243.

Bhogal, A. A., De Vis, J. B., Siero, J. C. W., Petersen, E. T., Luijten, P. R., Hendrikse, J., ... Hoogduin, H. (2016). The BOLD cerebrovascular reactivity response to progressive hypercapnia in young and elderly. NeuroImage, 139, 94-102.

Bonarjee, V. V. S. (2018). Arterial Stiffness: A Prognostic Marker in Coronary Heart Disease. Available Methods and Clinical Application. Frontiers in Cardiovascular Medicine, 5, 64. 
Bonithon-Kopp, C., Levenson, J., Scarabin, P. Y., Guillanneuf, M. T., Kirzin, J. M., Malmejac, A., \& Guize, L. (1993). Longitudinal associations between plasma viscosity and cardiovascular risk factors in a middle-aged French population. Atherosclerosis, 104(1-2), 173-182.

Braak, H., \& Braak, E. (1991). Neuropathological stageing of Alzheimer-related changes. Acta Neuropathologica, 82(4), 239-259.

Brackley, K. J., Ramsay, M. M., Broughton Pipkin, F., \& Rubin, P. C. (1999). The effect of the menstrual cycle on human cerebral blood flow: studies using Doppler ultrasound. Ultrasound in Obstetrics \& Gynecology: The Official Journal of the International Society of Ultrasound in Obstetrics and Gynecology, 14(1), 52-57.

Brodaty, H., Heffernan, M., Kochan, N. A., Draper, B., Trollor, J. N., Reppermund, S., ... Sachdev, P. S. (2013). Mild cognitive impairment in a community sample: the Sydney Memory and Ageing Study. Alzheimer's \& Dementia: The Journal of the Alzheimer's Association, 9(3), 310-317.e1.

Bucur, B., Madden, D. J., Spaniol, J., Provenzale, J. M., Cabeza, R., White, L. E., \& Huettel, S. A. (2008). Age-related slowing of memory retrieval: contributions of perceptual speed and cerebral white matter integrity. Neurobiology of Aging, 29(7), 1070-1079.

Burstein, B., Bank, L., \& Jarvik, L. F. (1980). Sex differences in cognitive functioning: evidence, determinants, implications. Human Development, 23(5), 289-313.

Bush, A., Chai, Y., Choi, S. Y., Vaclavu, L., Holland, S., Nederveen, A., ... Wood, J. (2018). Pseudo continuous arterial spin labeling quantification in anemic subjects with hyperemic cerebral blood flow. Magnetic Resonance Imaging, 47, 137-146.

Buxton, R. B. (2010). Interpreting oxygenation-based neuroimaging signals: the importance and the challenge of understanding brain oxygen metabolism. Frontiers in Neuroenergetics, $2,8$.

Cannon, R. O., 3rd. (1998). Role of nitric oxide in cardiovascular disease: focus on the endothelium. Clinical Chemistry, 44(8 Pt 2), 1809-1819.

Castonguay, N., Lussier, M., Bugaiska, A., Lord, C., \& Bherer, L. (2015). Executive functions in men and postmenopausal women. Journal of Clinical and Experimental Neuropsychology, 37(2), 193-208.

Chuang, S.-Y., Cheng, H.-M., Bai, C.-H., Yeh, W.-T., Chen, J.-R., \& Pan, W.-H. (2016). Blood Pressure, Carotid Flow Pulsatility, and the Risk of Stroke: A Community-Based Study. Stroke; $a$ Journal of Cerebral Circulation, 47(9), 2262-2268.

Cignarella, A., Kratz, M., \& Bolego, C. (2010). Emerging role of estrogen in the control of cardiometabolic disease. Trends in Pharmacological Sciences, 31(4), 183-189.

Cook, I. A., Leuchter, A. F., Morgan, M. L., Dunkin, J. J., Witte, E., David, S., ... Rosenberg, S. (2004). Longitudinal progression of subclinical structural brain disease in normal aging. The 
American Journal of Geriatric Psychiatry: Official Journal of the American Association for Geriatric Psychiatry, 12(2), 190-200.

Corrigan, F. E., 3rd, Al Mheid, I., Eapen, D. J., Hayek, S. S., Sher, S., Martin, G. S., \& Quyyumi, A. A. (2015). Low testosterone in men predicts impaired arterial elasticity and microvascular function. International Journal of Cardiology, 194, 94-99.

Coutinho, T. (2014). Arterial stiffness and its clinical implications in women. The Canadian Journal of Cardiology, 30(7), 756-764.

Coverdale, N. S., Gati, J. S., Opalevych, O., Perrotta, A., \& Shoemaker, J. K. (2014). Cerebral blood flow velocity underestimates cerebral blood flow during modest hypercapnia and hypocapnia. Journal of Applied Physiology, 117(10), 1090-1096.

Cust, M. P., Gangar, K. F., Hillard, T. C., \& Whitehead, M. I. (1990). A risk-benefit assessment of estrogen therapy in postmenopausal women. Drug Safety: An International Journal of Medical Toxicology and Drug Experience, 5(5), 345-358.

Davis, S. M., Ackerman, R. H., Correia, J. A., Alpert, N. M., Chang, J., Buonanno, F., ... Taveras, J. M. (1983). Cerebral blood flow and cerebrovascular CO2 reactivity in stroke-age normal controls. Neurology, Vol. 33, pp. 391-391. https://doi.org/10.1212/wnl.33.4.391

Dawson, J., \& Wyss, A. (2017). Chicken or the Egg? Hyperuricemia, Insulin Resistance, and Hypertension. Hypertension, Vol. 70, pp. 698-699. https://doi.org/10.1161/hypertensionaha.117.09685

Deeegan, B.M., Sorond, F.A., Galica, A., Lipsitz, L.A., O’Laighin, G.,\& Serrador, J.M. (2011). Elderly women regulate brain blood flow better than men do. Stroke; a Journal of Cerebral Circulation, 42(7), 1988-1993.

de la Colina, A. N., Badji, A., Sabra, D., Karakuzu, A., Joubert, S., Bherer, L., .. Girouard, H. (2019). Augmentation index is a predictor of cerebral blood flow across global grey matter in the elderly. JOURNAL OF CEREBRAL BLOOD FLOW AND METABOLISM, 39, 134-135. SAGE PUBLICATIONS INC 2455 TELLER RD, THOUSAND OAKS, CA 91320 USA.

de la Torre, J. C. (2002). Alzheimer disease as a vascular disorder: nosological evidence. Stroke; a Journal of Cerebral Circulation, 33(4), 1152-1162.

De Vis, J. B., Hendrikse, J., Bhogal, A., Adams, A., Kappelle, L. J., \& Petersen, E. T. (2015). Age-related changes in brain hemodynamics; A calibrated MRI study. Human Brain Mapping, 36(10), 3973-3987.

de Ziegler, D., Bessis, R., \& Frydman, R. (1991). Vascular resistance of uterine arteries: physiological effects of estradiol and progesterone. Fertility and Sterility, 55(4), 775-779. 
Deegan, B. M., Sorond, F. A., Galica, A., Lipsitz, L. A., O’Laighin, G., \& Serrador, J. M. (2011). Elderly women regulate brain blood flow better than men do. Stroke; a Journal of Cerebral Circulation, 42(7), 1988-1993.

Desjardins, M. (2015). Vascular correlates of aging in the brain: Evidence from imaging data. IRBM, 36(3), 158-165.

Dijk, J. M., Algra, A., van der Graaf, Y., Grobbee, D. E., Bots, M. L., \& SMART study group. (2005). Carotid stiffness and the risk of new vascular events in patients with manifest cardiovascular disease. The SMART study. European Heart Journal, 26(12), 1213-1220.

Dockery, F., Bulpitt, C. J., Donaldson, M., Fernandez, S., \& Rajkumar, C. (2003). The relationship between androgens and arterial stiffness in older men. Journal of the American Geriatrics Society, 51(11), 1627-1632.

DuBose, L. E., Boles Ponto, L. L., Moser, D. J., Harlynn, E., Reierson, L., \& Pierce, G. L. (2018). Higher Aortic Stiffness Is Associated With Lower Global Cerebrovascular Reserve Among Older Humans. Hypertension, 72(2), 476-482.

Duff, S. J., \& Hampson, E. (2001). A sex difference on a novel spatial working memory task in humans. Brain and Cognition, 47(3), 470-493.

DuPont, J. J., Kenney, R. M., Patel, A. R., \& Jaffe, I. Z. (2019a). Sex differences in mechanisms of arterial stiffness. British Journal of Pharmacology. https://doi.org/10.1111/bph.14624

Elias, M. F., Robbins, M. A., Budge, M. M., Abhayaratna, W. P., Dore, G. A., \& Elias, P. K. (2009a). Arterial pulse wave velocity and cognition with advancing age. Hypertension, 53(4), $668-673$.

Ellekjaer, H., Holmen, J., Indredavik, B., \& Terent, A. (1997). Epidemiology of stroke in Innherred, Norway, 1994 to 1996. Incidence and 30-day case-fatality rate. Stroke; a Journal of Cerebral Circulation, 28(11), 2180-2184.

Esposito, G., Van Horn, J. D., Weinberger, D. R., \& Berman, K. F. (1996). Gender differences in cerebral blood flow as a function of cognitive state with PET. Journal of Nuclear Medicine: Official Publication, Society of Nuclear Medicine, 37(4), 559-564.

Fossum, E., Høieggen, A., Moan, A., Nordby, G., Velund, T. L., \& Kjeldsen, S. E. (1997). Whole blood viscosity, blood pressure and cardiovascular risk factors in healthy blood donors. Blood Pressure, 6(3), 161-165.

Fukuhara, M., Matsumura, K., Ansai, T., Takata, Y., Sonoki, K., Akifusa, S., ... Takehara, T. (2006a). Prediction of cognitive function by arterial stiffness in the very elderly. Circulation Journal: Official Journal of the Japanese Circulation Society, 70(6), 756-761.

Gale, S. D., Baxter, L., Connor, D. J., Herring, A., \& Comer, J. (2007). Sex differences on the Rey Auditory Verbal Learning Test and the Brief Visuospatial Memory Test-Revised in the 
elderly: Normative data in 172 participants. Journal of Clinical and Experimental Neuropsychology, 29(5), 561-567.

Garn, S. M., Smith, N. J., \& Clark, D. C. (1975). Lifelong differences in hemoglobin levels between Blacks and Whites. Journal of the National Medical Association, 67(2), 91-96.

Gaser, C. (2016). Structural MRI: Morphometry. In M. Reuter \& C. Montag (Eds.), Neuroeconomics (pp. 399-409). Berlin, Heidelberg: Springer Berlin Heidelberg.

Gatzka, C. D., Kingwell, B. A., Cameron, J. D., Berry, K. L., Liang, Y.-L., Dewar, E. M., ... Dart, A. M. (2001). Gender differences in the timing of arterial wave reflection beyond differences in body height. Journal of Hypertension, Vol. 19, pp. 2197-2203.

https://doi.org/10.1097/00004872-200112000-00013

Gauthier, C. J., Desjardins-Crépeau, L., Madjar, C., Bherer, L., \& Hoge, R. D. (2012a). Absolute quantification of resting oxygen metabolism and metabolic reactivity during functional activation using QUO2 MRI. NeuroImage, 63(3), 1353-1363.

Gauthier, C. J., \& Hoge, R. D. (2012a). Magnetic resonance imaging of resting OEF and $\mathrm{CMRO} 2$ using a generalized calibration model for hypercapnia and hyperoxia. NeuroImage, $60(2), 1212-1225$.

Gauthier, C. J., Lefort, M., Mekary, S., Desjardins-Crépeau, L., Skimminge, A., Iversen, P., ... Hoge, R. D. (2015a). Hearts and minds: linking vascular rigidity and aerobic fitness with cognitive aging. Neurobiology of Aging, 36(1), 304-314.

Gauthier, C. J., Madjar, C., Desjardins-Crépeau, L., Bellec, P., Bherer, L., \& Hoge, R. D. (2013a). Age dependence of hemodynamic response characteristics in human functional magnetic resonance imaging. Neurobiology of Aging, 34(5), 1469-1485.

Geary, G. G., Krause, D. N., \& Duckles, S. P. (1998). Estrogen reduces myogenic tone through a nitric oxide-dependent mechanism in rat cerebral arteries. The American Journal of Physiology, 275(1), H292-H300.

Glover, G. H. (1999). Deconvolution of Impulse Response in Event-Related BOLD fMRI1. NeuroImage, 9(4), 416-429.

Goddard, L., Dritschel, B., \& Burton, A. (1998). Gender differences in the dual-task effects on autobiographical memory retrieval during social problem solving. British Journal of Psychology , 89(4), 611-627.

Golay, X., \& Petersen, E. T. (2006). Arterial spin labeling: benefits and pitfalls of high magnetic field. Neuroimaging Clinics of North America, 16(2), 259-268, x.

Goldman, H., Skelley, E. B., Sandman, C. A., Kastin, A. J., \& Murphy, S. (1976). Hormones and regional brain blood flow. Pharmacology, Biochemistry, and Behavior, 5(Suppl 1), 165-169. 
Gorelick, P. B., Nyenhuis, D., American Society of Hypertension Writing Group, Materson, B. J., Calhoun, D. A., Elliott, W. J., ... Townsend, R. R. (2012). Blood pressure and treatment of persons with hypertension as it relates to cognitive outcomes including executive function. Journal of the American Society of Hypertension: JASH, 6(5), 309-315.

Gunning-Dixon, F. M., \& Raz, N. (2000). The cognitive correlates of white matter abnormalities in normal aging: a quantitative review. Neuropsychology, 14(2), 224-232.

Halani, S., Kwinta, J. B., Golestani, A. M., Khatamian, Y. B., \& Jean Chen, J. (2015).

Comparing cerebrovascular reactivity measured using BOLD and cerebral blood flow MRI: The effect of basal vascular tension on vasodilatory and vasoconstrictive reactivity. NeuroImage, Vol. 110, pp. 110-123. https://doi.org/10.1016/j.neuroimage.2015.01.050

Halpern, D. F., \& LaMay, M. L. (2000). The Smarter Sex: A Critical Review of Sex Differences in Intelligence. Educational Psychology Review, 12(2), 229-246.

Hanon, O., Haulon, S., Lenoir, H., Seux, M.-L., Rigaud, A.-S., Safar, M., ... Forette, F. (2005). Relationship between arterial stiffness and cognitive function in elderly subjects with complaints of memory loss. Stroke; a Journal of Cerebral Circulation, 36(10), 2193-2197.

Haratz, S., Weinstein, G., \& Molshazki, N. (2015). Impaired cerebral hemodynamics and cognitive performance in patients with atherothrombotic disease. Journal of. Retrieved from https://content.iospress.com/articles/journal-of-alzheimers-disease/jad150052

Hayes, A. F. (2017). Introduction to Mediation, Moderation, and Conditional Process Analysis, Second Edition: A Regression-Based Approach. Guilford Publications.

Head, D., Bugg, J. M., Goate, A. M., Fagan, A. M., Mintun, M. A., Benzinger, T., ... Morris, J. C. (2012). Exercise Engagement as a Moderator of the Effects of APOE Genotype on Amyloid Deposition. Archives of Neurology, 69(5), 636-643.

Herlitz, A., Nilsson, L. G., \& Bäckman, L. (1997). Gender differences in episodic memory. Memory \& Cognition, 25(6), 801-811.

Herlitz, A., \& Rehnman, J. (2008). Sex differences in episodic memory. Current Directions in Psychological Science. Retrieved from https://journals.sagepub.com/doi/abs/10.1111/j.1467-8721.2008.00547.x

Herment, A., Kachenoura, N., Lefort, M., Bensalah, M., Dogui, A., Frouin, F., ... De Cesare, A. (2010). Automated segmentation of the aorta from phase contrast MR images: validation against expert tracing in healthy volunteers and in patients with a dilated aorta. Journal of Magnetic Resonance Imaging: JMRI, 31(4), 881-888.

Ho, S. C., Woo, J., Sham, A., Chan, S. G., \& Yu, A. L. (2001). A 3-year follow-up study of social, lifestyle and health predictors of cognitive impairment in a Chinese older cohort. International Journal of Epidemiology, 30(6), 1389-1396. 
Hyde, J. S., \& Linn, M. C. (1988). Gender differences in verbal ability: A meta-analysis. Psychological Bulletin, 104(1), 53.

Ikram, M., Zaccai, K., Poels, M., Verwoert, G., Vernooij, M., Witteman, J., ... Breteler, M. (2011). Arterial stiffness is associated with cerebral small vessel disease. Alzheimer's \& Dementia: The Journal of the Alzheimer's Association, 7(4), S295.

Intzandt, B., Sabra, D., Foster, C., Desjardins-Crépeau, L., Hoge, R. D., Steele, C. J., ... Gauthier, C. J. (2019). Higher cardiovascular fitness level is associated with lower cerebrovascular reactivity and perfusion in healthy older adults. Journal of Cerebral Blood Flow \& Metabolism, p. 0271678X1986287. https://doi.org/10.1177/0271678x19862873

Iulita, M. F., Noriega de la Colina, A., \& Girouard, H. (2018). Arterial stiffness, cognitive impairment and dementia: confounding factor or real risk? Journal of Neurochemistry, 144(5), $527-548$.

J. Larner, A. (2012). Mini-Mental Parkinson (MMP) as a Dementia Screening Test: Comparison with the Mini-Mental State Examination (MMSE). Current Aging Sciencee, 5(2), 136-139.

Jaruchart, T., Suwanwela, N. C., Tanaka, H., \& Suksom, D. (2016). Arterial stiffness is associated with age-related differences in cerebrovascular conductance. Experimental Gerontology, Vol. 73, pp. 59-64. https://doi.org/10.1016/j.exger.2015.11.006

Jefferson, A. L., Cambronero, F. E., Liu, D., Moore, E. E., Neal, J. E., Terry, J. G., .. Carr, J. J. (2018). Higher Aortic Stiffness is Related to Lower Cerebral Blood Flow and Preserved Cerebrovascular Reactivity in Older Adults. Circulation. https://doi.org/10.1161/CIRCULATIONAHA.118.032410

Jochemsen, H. M., Muller, M., Bots, M. L., Scheltens, P., Vincken, K. L., Mali, W. P. T. M., ... SMART Study Group. (2015). Arterial stiffness and progression of structural brain changes: The SMART-MR study. Neurology, 84(5), 448-455.

Johnson, K. A., Gregas, M., Becker, J. A., Kinnecom, C., Salat, D. H., Moran, E. K., ... Greenberg, S. M. (2007). Imaging of amyloid burden and distribution in cerebral amyloid angiopathy. Annals of Neurology, 62(3), 229-234.

Karas, R. H., Patterson, B. L., \& Mendelsohn, M. E. (1994). Human vascular smooth muscle cells contain functional estrogen receptor. Circulation, 89(5), 1943-1950.

Katulska, K., Wykrętowicz, M., Minczykowski, A., Krauze, T., Milewska, A., Piskorski, J., ... Wykrętowicz, A. (2014). Gray matter volume in relation to cardio-vascular stiffness. Journal of the Neurological Sciences, 343(1-2), 100-104.

Kennison, S. M. (2003). Sex differences in cognitive abilities (3rd edition). Diane F. Halpern. Lawrence Erlbaum Associates, Mahwah, NJ, 2000. No. of pages 420. ISBN 0-8058-2792-7. 
Price: \$39.95. Applied Cognitive Psychology, Vol. 17, pp. 375-376.

https://doi.org/10.1002/acp.883

Kim, J. Y., Yoon, J., Cho, M., Lee, B.-K., Karimi, A., \& Shin, S. (2013). Blood characteristics effect on pulse wave velocity. Clinical Hemorheology and Microcirculation, 55(1), 193-203.

Kim, J.-Y., Park, J. B., Kim, D. S., Kim, K. S., Jeong, J. W., Park, J. C., ... KAAS investigators. (2014). Gender Difference in Arterial Stiffness in a Multicenter Cross-Sectional Study: The Korean Arterial Aging Study (KAAS). The Pulse of the Montana State Nurses' Association, 2(1-4), 11-17.

Kimberly, W. T., Lima, F. O., O’Connor, S., \& Furie, K. L. (2013). Sex differences and hemoglobin levels in relation to stroke outcomes. Neurology, Vol. 80, pp. 719-724. https://doi.org/10.1212/wnl.0b013e31828250ff

Kramer, J. H., Mungas, D., Reed, B. R., Wetzel, M. E., Burnett, M. M., Miller, B. L., ... Chui, H. C. (2007). Longitudinal MRI and cognitive change in healthy elderly. Neuropsychology, 21(4), 412-418.

Krause, D. N., Duckles, S. P., \& Pelligrino, D. A. (2006). Influence of sex steroid hormones on cerebrovascular function. Journal of Applied Physiology, 101(4), 1252-1261.

Krejza, J., Mariak, Z., Huba, M., Wolczynski, S., \& Lewko, J. (2001). Effect of endogenous estrogen on blood flow through carotid arteries. Stroke; a Journal of Cerebral Circulation, 32(1), 30-36.

Krejza, J., Rudzinski, W., Arkuszewski, M., Onuoha, O., \& Melhem, E. R. (2013). Cerebrovascular reactivity across the menstrual cycle in young healthy women. The Neuroradiology Journal, 26(4), 413-419.

Krejza, J., Siemkowicz, J., Sawicka, M., Szylak, A., Kochanowicz, J., Mariak, Z., ... Bert, R. (2003). Oscillations of cerebrovascular resistance throughout the menstrual cycle in healthy women. Ultrasound in Obstetrics \& Gynecology: The Official Journal of the International Society of Ultrasound in Obstetrics and Gynecology, 22(6), 627-632.

Kurlowicz, L., \& Wallace, M. (1999). The Mini-Mental State Examination (MMSE). Journal of Gerontological Nursing, 25(5), 8-9.

Kyriazis, J., Tzanakis, I., Stylianou, K., Katsipi, I., Moisiadis, D., Papadaki, A., .. Daphnis, E. (2011). Low serum testosterone, arterial stiffness and mortality in male haemodialysis patients. Nephrology, Dialysis, Transplantation: Official Publication of the European Dialysis and Transplant Association - European Renal Association, 26(9), 2971-2977.

Lee, G., Choi, S., Kim, K., Yun, J., Son, J. S., Jeong, S., ... Park, S. M. (2018). Association of Hemoglobin Concentration and Its Change With Cardiovascular and All-Cause Mortality. Journal of the American Heart Association. https://doi.org/10.1161/JAHA.117.007723 
Lee, S.-T., Jung, K.-H., \& Lee, Y.-S. (2007). Decreased vasomotor reactivity in Alzheimer's disease. Journal of Clinical Neurology, 3(1), 18-23.

Levenson, J., Simon, A. C., Cambien, F. A., \& Beretti, C. (1987). Cigarette smoking and hypertension. Factors independently associated with blood hyperviscosity and arterial rigidity. Arteriosclerosis , 7(6), 572-577.

Li, X., Wang, D., Auerbach, E. J., Moeller, S., Ugurbil, K., \& Metzger, G. J. (2015). Theoretical and experimental evaluation of multi-band EPI for high-resolution whole brain pCASL Imaging. NeuroImage, 106, 170-181.

Lilamand, M., Vidal, J.-S., Plichart, M., De Jong, L. W., Duron, E., \& Hanon, O. (2016). Arterial stiffness and medial temporal lobe atrophy in elders with memory disorders. Journal of Hypertension, 34(7), 1331-1337.

Lim, S. L., Gao, Q., Nyunt, M. S. Z., Gong, L., Lunaria, J. B., Lim, M. L., .. Ng, T. P. (2016). Vascular Health Indices and Cognitive Domain Function: Singapore Longitudinal Ageing Studies. Journal of Alzheimer's Disease: JAD, 50(1), 27-40.

Liu, T. T., \& Wong, E. C. (2005). A signal processing model for arterial spin labeling functional MRI. NeuroImage, 24(1), 207-215.

Lu, H., Xu, F., Rodrigue, K. M., Kennedy, K. M., Cheng, Y., Flicker, B., ... Park, D. C. (2011). Alterations in cerebral metabolic rate and blood supply across the adult lifespan. Cerebral Cortex , 21(6), 1426-1434.

Maas, A. H. E. M., A H E, \& Appelman, Y. E. A. (2010a). Gender differences in coronary heart disease. Netherlands Heart Journal, Vol. 18, pp. 598-603.

https://doi.org/10.1007/s12471-010-0841-y

Madden, D. J., Whiting, W. L., Huettel, S. A., White, L. E., MacFall, J. R., \& Provenzale, J. M. (2004). Diffusion tensor imaging of adult age differences in cerebral white matter: relation to response time. NeuroImage, 21(3), 1174-1181.

Magness, R. R., Parker, C. R., Jr, \& Rosenfeld, C. R. (1993). Systemic and uterine responses to chronic infusion of estradiol-17 beta. The American Journal of Physiology, 265(5 Pt 1), E690-E698.

Maillard, P., Mitchell, G. F., Himali, J. J., Beiser, A., Tsao, C. W., Pase, M. P., ... DeCarli, C. (2016). Effects of Arterial Stiffness on Brain Integrity in Young Adults From the Framingham Heart Study. Stroke; a Journal of Cerebral Circulation, 47(4), 1030-1036.

Martin, P. J., Evans, D. H., \& Naylor, A. R. (1994). Transcranial color-coded sonography of the basal cerebral circulation. Reference data from 115 volunteers. Stroke; a Journal of Cerebral Circulation, 25(2), 390-396. 
Matteis, M., Troisi, E., Monaldo, B. C., Caltagirone, C., \& Silvestrini, M. (1998a). Age and sex differences in cerebral hemodynamics: a transcranial Doppler study. Stroke; a Journal of Cerebral Circulation, 29(5), 963-967.

Mawuenyega, K. G., Sigurdson, W., Ovod, V., Munsell, L., Kasten, T., Morris, J. C., ... Bateman, R. J. (2010). Decreased clearance of CNS beta-amyloid in Alzheimer's disease. Science, 330(6012), 1774.

McCarrey, A. C., An, Y., Kitner-Triolo, M. H., Ferrucci, L., \& Resnick, S. M. (2016). Sex differences in cognitive trajectories in clinically normal older adults. Psychology and Aging, 31(2), 166-175.

McGowan, J. F., \& Duka, T. (2000). Hemispheric lateralisation in a manual-verbal task combination: the role of modality and gender. Neuropsychologia, 38(7), 1018-1027.McNeill, A. M., Zhang, C., Stanczyk, F. Z., Duckles, S. P., \& Krause, D. N. (2002). Estrogen increases endothelial nitric oxide synthase via estrogen receptors in rat cerebral blood vessels: effect preserved after concurrent treatment with medroxyprogesterone acetate or progesterone. Stroke; a Journal of Cerebral Circulation, 33(6), 1685-1691.

Meinz, E. J., \& Salthouse, T. A. (1998). Is age kinder to females than to males? Psychonomic Bulletin \& Review, 5(1), 56-70.

Members, W. G., Lloyd-Jones, D., Adams, R. J., Brown, T. M., Carnethon, M., Dai, S., ... Others. (2010). Executive summary: heart disease and stroke statistics-2010 update: a report from the American Heart Association. Circulation, 121(7), 948-954.

Mendelsohn, M. E., \& Karas, R. H. (1999). The protective effects of estrogen on the cardiovascular system. The New England Journal of Medicine, 340(23), 1801-1811.

Mitchell, G. F. (2009). Arterial Stiffness and Wave Reflection: Biomarkers of Cardiovascular Risk. Artery Research, 3(2), 56-64.

Mitchell, G. F. (2014). Arterial Stiffness and Hypertension. Hypertension, Vol. 64, pp. 210-214. https://doi.org/10.1161/hypertensionaha.114.03449

Mitchell, G. F., van Buchem, M. A., Sigurdsson, S., Gotal, J. D., Jonsdottir, M. K., Kjartansson, Ó., ... Launer, L. J. (2011). Arterial stiffness, pressure and flow pulsatility and brain structure and function: the Age, Gene/Environment Susceptibility--Reykjavik study. Brain: A Journal of Neurology, 134(Pt 11), 3398-3407.

Murphy, W. G. (2014). The sex difference in haemoglobin levels in adults - Mechanisms, causes, and consequences. Blood Reviews, Vol. 28, pp. 41-47.

https://doi.org/10.1016/j.blre.2013.12.003 
Murrell, C. J., Cotter, J. D., Thomas, K. N., Lucas, S. J. E., Williams, M. J. A., \& Ainslie, P. N. (2013). Cerebral blood flow and cerebrovascular reactivity at rest and during sub-maximal exercise: effect of age and 12-week exercise training. Age, 35(3), 905-920.

Narkiewicz, K., Kjeldsen, S. E., \& Hedner, T. (2006). Hypertension and cardiovascular disease in women: Progress towards better understanding of gender-specific differences? Blood Pressure, 15(2), 68-70.

Nevo, O., Soustiel, J. F., \& Thaler, I. (2007). Cerebral blood flow is increased during controlled ovarian stimulation. American Journal of Physiology. Heart and Circulatory Physiology, 293(6), H3265-H3269.

Novak, V. (2012a). Cognition and Hemodynamics. Current Cardiovascular Risk Reports, 6(5), 380-396.

O’Rourke, M. F., \& Safar, M. E. (2005). Relationship between aortic stiffening and microvascular disease in brain and kidney: cause and logic of therapy. Hypertension, 46(1), 200-204.

Ogola, B. O., Zimmerman, M. A., Clark, G. L., Abshire, C. M., Gentry, K. M., Miller, K. S., \& Lindsey, S. H. (2018). New insights into arterial stiffening: does sex matter? American Journal of Physiology. Heart and Circulatory Physiology, 315(5), H1073-H1087.

Okamoto, Y., Yamamoto, T., Kalaria, R. N., Senzaki, H., Maki, T., Hase, Y., ... Ihara, M. (2012). Cerebral hypoperfusion accelerates cerebral amyloid angiopathy and promotes cortical microinfarcts. Acta Neuropathologica, 123(3), 381-394.

Oláh, L., Valikovics, A., Bereczki, D., Fülesdi, B., Munkácsy, C., \& Csiba, L. (2000). Gender-Related Differences in Acetazolamide-Induced Cerebral Vasodilatory Response: A Transcranial Doppler Study. Journal of Neuroimaging, Vol. 10, pp. 151-156. https://doi.org/10.1111/jon2000103151

Orshal, J. M., \& Khalil, R. A. (2004). Gender, sex hormones, and vascular tone. American Journal of Physiology. Regulatory, Integrative and Comparative Physiology, 286(2), R233-R249.

Ostrovskaya, M. A., Rojas, M., Kupferman, J. C., Lande, M. B., Paterno, K., Brosgol, Y., \& Pavlakis, S. G. (2015). Executive function and cerebrovascular reactivity in pediatric hypertension. Journal of Child Neurology, 30(5), 543-546.

Painter, P. R. (2008). The velocity of the arterial pulse wave: a viscous-fluid shock wave in an elastic tube. Theoretical Biology \& Medical Modelling, 5, 15.

Parkhurst, K. L., Lin, H.-F., Devan, A. E., Barnes, J. N., Tarumi, T., \& Tanaka, H. (2012). Contribution of blood viscosity in the assessment of flow-mediated dilation and arterial stiffness. Vascular Medicine , 17(4), 231-234. 
Pase, M. P., Himali, J. J., Mitchell, G. F., Beiser, A., Maillard, P., Tsao, C., ... Seshadri, S. (2016). Association of Aortic Stiffness With Cognition and Brain Aging in Young and Middle-Aged Adults: The Framingham Third Generation Cohort Study. Hypertension, 67(3), $513-519$.

Penny, W. D., Friston, K. J., Ashburner, J. T., Kiebel, S. J., \& Nichols, T. E. (2011). Statistical Parametric Mapping: The Analysis of Functional Brain Images. Elsevier.

Pepine, C. J., Nichols, W. W., \& Pauly, D. F. (2006). Estrogen and different aspects of vascular disease in women and men. Circulation Research, 99(5), 459-461.

Petersen, R. C., Roberts, R. O., Knopman, D. S., Geda, Y. E., Cha, R. H., Pankratz, V. S., ... Rocca, W. A. (2010). Prevalence of mild cognitive impairment is higher in men. The Mayo Clinic Study of Aging. Neurology, 75(10), 889-897.

Petrea, R. E., Beiser, A. S., Seshadri, S., Kelly-Hayes, M., Kase, C. S., \& Wolf, P. A. (2009). Gender differences in stroke incidence and poststroke disability in the Framingham heart study. Stroke; a Journal of Cerebral Circulation, 40(4), 1032-1037.

Poels, M. M. F., van Oijen, M., Mattace-Raso, F. U. S., Hofman, A., Koudstaal, P. J., Witteman, J. C. M., \& Breteler, M. M. B. (2007b). Arterial stiffness, cognitive decline, and risk of dementia: the Rotterdam study. Stroke; a Journal of Cerebral Circulation, 38(3), 888-892.

Qiu, H., Depre, C., Ghosh, K., Resuello, R. G., Natividad, F. F., Rossi, F., ... Vatner, S. F. (2007). Mechanism of gender-specific differences in aortic stiffness with aging in nonhuman primates. Circulation, 116(6), 669-676.

Rajkumar, C., Kingwell, B. A., Cameron, J. D., Waddell, T., Mehra, R., Christophidis, N., ... Dart, A. M. (1997). Hormonal therapy increases arterial compliance in postmenopausal women. Journal of the American College of Cardiology, 30(2), 350-356.

Read, S., Pedersen, N. L., Gatz, M., Berg, S., Vuoksimaa, E., Malmberg, B., .. McClearn, G. E. (2006). Sex differences after all those years? Heritability of cognitive abilities in old age. The Journals of Gerontology. Series B, Psychological Sciences and Social Sciences, 61(3), P137-P143.

Regnault, V., Thomas, F., Safar, M. E., Osborne-Pellegrin, M., Khalil, R. A., Pannier, B., \& Lacolley, P. (2012). Sex difference in cardiovascular risk: role of pulse pressure amplification. Journal of the American College of Cardiology, 59(20), 1771-1777.

Reich, T., \& Rusinek, H. (1989). Cerebral cortical and white matter reactivity to carbon dioxide. Stroke; a Journal of Cerebral Circulation, 20(4), 453-457.

Resnick, S. M., Maki, P. M., Golski, S., Kraut, M. A., \& Zonderman, A. B. (1998). Effects of estrogen replacement therapy on PET cerebral blood flow and neuropsychological performance. Hormones and Behavior, 34(2), 171-182. 
Robison, L.S., Gannon, O.J., Salinero, A.E.,\& Zuloaga, K.L. (2019) Contributions of sex to cerebrovascular function and pathology. Brain Research, 1710, 43-60.

Rodrigue, K. M., Kennedy, K. M., Devous, M. D., Sr, Rieck, J. R., Hebrank, A. C., Diaz-Arrastia, R., ... Park, D. C. (2012). $\beta$-Amyloid burden in healthy aging: regional distribution and cognitive consequences. Neurology, 78(6), 387-395.

Rodriguez, G., Warkentin, S., Risberg, J., \& Rosadini, G. (1988). Sex differences in regional cerebral blood flow. Journal of Cerebral Blood Flow and Metabolism: Official Journal of the International Society of Cerebral Blood Flow and Metabolism, 8(6), 783-789.

Rossi, P., Francès, Y., Kingwell, B. A., \& Ahimastos, A. A. (2011). Gender differences in artery wall biomechanical properties throughout life. Journal of Hypertension, 29(6), 1023-1033.

Sarrel, P. M. (1990). Ovarian hormones and the circulation. Maturitas, 12(3), 287-298.

Schmahmann, J. D. (2003a). Vascular syndromes of the thalamus. Stroke; a Journal of Cerebral Circulation, 34(9), 2264-2278.

Scuteri, A., Brancati, A. M., Gianni, W., Assisi, A., \& Volpe, M. (2005). Arterial stiffness is an independent risk factor for cognitive impairment in the elderly: a pilot study. Journal of Hypertension, 23(6), 1211-1216.

Segers, P., Rietzschel, E. R., De Buyzere, M. L., Vermeersch, S. J., De Bacquer, D., Van Bortel, L. M., ... Verdonck, P. R. (2007a). Noninvasive (Input) Impedance, Pulse Wave Velocity, and Wave Reflection in Healthy Middle-Aged Men and Women. Hypertension, Vol. 49, pp. 1248-1255. https://doi.org/10.1161/hypertensionaha.106.085480

Seo, E. H., Lee, D. Y., Choo, I. H., Kim, S. G., Kim, K. W., Youn, J. C., ... Woo, J. I. (2008). Normative study of the Stroop Color and Word Test in an educationally diverse elderly population. International Journal of Geriatric Psychiatry, 23(10), 1020-1027.

Shaw, L. J., Merz, C. N. B., Pepine, C. J., Reis, S. E., Bittner, V., Kelsey, S. F., ... Others. (2006). Insights from the NHLBI-Sponsored Women's Ischemia Syndrome Evaluation (WISE) Study: Part I: gender differences in traditional and novel risk factors, symptom evaluation, and gender-optimized diagnostic strategies. Journal of the American College of Cardiology, 47(3 Supplement), S4-S20.

Shaywitz, S. E. (1999). Effect of Estrogen on Brain Activation Patterns in Postmenopausal Women During Working Memory Tasks. JAMA, Vol. 281, p. 1197. https://doi.org/10.1001/jama.281.13.1197

Sheifer, S. E., Canos, M. R., Weinfurt, K. P., Arora, U. K., Mendelsohn, F. O., Gersh, B. J., \& Weissman, N. J. (2000). Sex differences in coronary artery size assessed by intravascular ultrasound. American Heart Journal, 139(4), 649-653. 
Sherwin, B. B. (1996). S42 Estrogen and memory in women. Maturitas, Vol. 27, p. 36. https://doi.org/10.1016/s0378-5122(97)80945-0

Sherwin, B. B. (1997). Estrogen effects on cognition in menopausal women. Neurology, $48(5$ Suppl 7), S21-S26.

Sherwin, B. B. (2003). Estrogen and cognitive functioning in women. Endocrine Reviews, 24(2), $133-151$.

Silvennoinen, M. J., Kettunen, M. I., \& Kauppinen, R. A. (2003). Effects of hematocrit and oxygen saturation level on blood spin-lattice relaxation. Magnetic Resonance in Medicine: An Official Journal of the International Society for Magnetic Resonance in Medicine, 49(3), $568-571$.

Silvestrini, M., Pasqualetti, P., Baruffaldi, R., Bartolini, M., Handouk, Y., Matteis, M., ... Vernieri, F. (2006a). Cerebrovascular reactivity and cognitive decline in patients with Alzheimer disease. Stroke; a Journal of Cerebral Circulation, 37(4), 1010-1015.

Singer, J., Trollor, J. N., Baune, B. T., Sachdev, P. S., \& Smith, E. (2014). Arterial stiffness, the brain and cognition: a systematic review. Ageing Research Reviews, 15, 16-27.

Singer, J., Trollor, J. N., Crawford, J., O’Rourke, M. F., Baune, B. T., Brodaty, H., ... Smith, E. (2013a). The association between pulse wave velocity and cognitive function: the Sydney Memory and Ageing Study. PloS One, 8(4), e61855.

Sizemore, B. C., Barrow, G., Johnson, B. D., Kip, K., von Mering, G. O., Kerensky, R. A., ... Pepine, C. J. (2005). Pulse pressure is a stronger predictor of mortality and cardiovascular events than systolic blood pressure in women: A report from the NHLBI-sponsored women's ischemia syndrome evaluation (WISE) study. Circulation, 112, U742-U742. LIPPINCOTT WILLIAMS \& WILKINS 530 WALNUT ST, PHILADELPHIA, PA 19106-3261 USA.

Smith, W. C., Lowe, G. D., Lee, A. J., \& Tunstall-Pedoe, H. (1992). Rheological determinants of blood pressure in a Scottish adult population. Journal of Hypertension, 10(5), 467-472.

Stojadinović, B., Tenne, T., Zikich, D., Rajković, N., Milošević, N., Lazović, B., \& Žikić, D. (2015). Effect of viscosity on the wave propagation: Experimental determination of compression and expansion pulse wave velocity in fluid-fill elastic tube. Journal of Biomechanics, 48(15), 3969-3974.

Suchy, Y. (2015). Executive Functioning: A Comprehensive Guide for Clinical Practice. Oxford University Press.

Sugawara, N., Yasui-Furukori, N., Umeda, T., Kaneda, A., Sato, Y., Takahashi, I., ... Kaneko, S. (2010). Comparison of ankle-brachial pressure index and pulse wave velocity as markers of cognitive function in a community-dwelling population. BMC Psychiatry, 10, 46. 
Sullivan, M. L., Martinez, C. M., Gennis, P., \& John Gallagher, E. (1998). The cardiac toxicity of anabolic steroids. Progress in Cardiovascular Diseases, Vol. 41, pp. 1-15. https://doi.org/10.1016/s0033-0620(98)80019-4

Tardif, C. L., Gauthier, C. J., Steele, C. J., Bazin, P.-L., Schäfer, A., Schaefer, A., ... Villringer, A. (2016). Advanced MRI techniques to improve our understanding of experience-induced neuroplasticity. NeuroImage, 131, 55-72.

Tardif, C. L., Steele, C. J., Lampe, L., Bazin, P.-L., Ragert, P., Villringer, A., \& Gauthier, C. J. (2017). Investigation of the confounding effects of vasculature and metabolism on computational anatomy studies. NeuroImage, 149, 233-243.

Tarumi, T., Ayaz Khan, M., Liu, J., Tseng, B. Y., Tseng, B. M., Parker, R., ... Zhang, R. (2014). Cerebral hemodynamics in normal aging: central artery stiffness, wave reflection, and pressure pulsatility. Journal of Cerebral Blood Flow and Metabolism: Official Journal of the International Society of Cerebral Blood Flow and Metabolism, 34(6), 971-978.

Tarumi, T., de Jong, D. L. K., Zhu, D. C., Tseng, B. Y., Liu, J., Hill, C., ... Zhang, R. (2015). Central artery stiffness, baroreflex sensitivity, and brain white matter neuronal fiber integrity in older adults. NeuroImage, 110, 162-170.

Tarumi, T., Gonzales, M. M., Fallow, B., Nualnim, N., Pyron, M., Tanaka, H., \& Haley, A. P. (2013b). Central artery stiffness, neuropsychological function, and cerebral perfusion in sedentary and endurance-trained middle-aged adults. Journal of Hypertension, 31(12), 2400-2409.

Tarumi, T., Shah, F., Tanaka, H., \& Haley, A. P. (2011). Association between central elastic artery stiffness and cerebral perfusion in deep subcortical gray and white matter. American Journal of Hypertension, 24(10), 1108-1113.

Tarumi, T., \& Zhang, R. (2018). Cerebral blood flow in normal aging adults: cardiovascular determinants, clinical implications, and aerobic fitness. Journal of Neurochemistry, 144(5), 595-608.

Tegeler, C. H., Crutchfield, K., Katsnelson, M., Kim, J., Tang, R., Passmore Griffin, L., ... Evans, G. (2013). Transcranial Doppler velocities in a large, healthy population. Journal of Neuroimaging: Official Journal of the American Society of Neuroimaging, 23(3), 466-472.

Thomas, B. P., Yezhuvath, U. S., Tseng, B. Y., Liu, P., Levine, B. D., Zhang, R., \& Lu, H. (2013). Life-long aerobic exercise preserved baseline cerebral blood flow but reduced vascular reactivity to CO2. Journal of Magnetic Resonance Imaging: JMRI, 38(5), 1177-1183.

Thompson, P. D., Cullinane, E. M., Sady, S. P., Chenevert, C., Saritelli, A. L., Sady, M. A., \& Herbert, P. N. (1989). Contrasting effects of testosterone and stanozolol on serum lipoprotein levels. JAMA: The Journal of the American Medical Association, 261(8), 1165-1168. 
Tombaugh, T. N., \& McIntyre, N. J. (1992). The mini-mental state examination: a comprehensive review. Journal of the American Geriatrics Society, 40(9), 922-935.

Tomoto, T., Sugawara, J., Nogami, Y., Aonuma, K., \& Maeda, S. (2015). The influence of central arterial compliance on cerebrovascular hemodynamics: insights from endurance training intervention. Journal of Applied Physiology, 119(5), 445-451.

Towfighi, A., Zheng, L., \& Ovbiagele, B. (2009). Sex-specific trends in midlife coronary heart disease risk and prevalence. Archives of Internal Medicine, 169(19), 1762-1766.

Tsao, C. W., Seshadri, S., Beiser, A. S., Westwood, A. J., Decarli, C., Au, R., ... Mitchell, G. F. (2013). Relations of arterial stiffness and endothelial function to brain aging in the community. Neurology, 81(11), 984-991.

Tun, P. A., \& Lachman, M. E. (2008). Age differences in reaction time and attention in a national telephone sample of adults: education, sex, and task complexity matter. Developmental Psychology, 44(5), 1421-1429.

Vahlquist, B. O., \& Others. (1950). The cause of sexual differences in erythrocyte, hemoglobin and serum iron levels in human adults. Blood, J. Hematol., 5, 874-875.

Van der Elst, W., Van Boxtel, M. P. J., Van Breukelen, G. J. P., \& Jolles, J. (2006). The Stroop color-word test: influence of age, sex, and education; and normative data for a large sample across the adult age range. Assessment, 13(1), 62-79.

Vernooij, M. W., Ikram, M. A., Vrooman, H. A., Wielopolski, P. A., Krestin, G. P., Hofman, A., ... Breteler, M. M. B. (2009). White matter microstructural integrity and cognitive function in a general elderly population. Archives of General Psychiatry, 66(5), 545-553.

Vlachopoulos, C., Ioakeimidis, N., Miner, M., Aggelis, A., Pietri, P., Terentes-Printzios, D., ... Stefanadis, C. (2014). Testosterone deficiency: a determinant of aortic stiffness in men. Atherosclerosis, 233(1), 278-283.

Voyer, D., Voyer, S., \& Bryden, M. P. (1995). Magnitude of sex differences in spatial abilities: a meta-analysis and consideration of critical variables. Psychological Bulletin, 117(2), 250-270.

Vriens, E. M., Kraaier, V., Musbach, M., Wieneke, G. H., \& van Huffelen, A. C. (1989). Transcranial pulsed doppler measurements of blood velocity in the middle cerebral artery: Reference values at rest and during hyperventilation in healthy volunteers in relation to age and sex. Ultrasound in Medicine \& Biology, Vol. 15, pp. 1-8.

https://doi.org/10.1016/0301-5629(89)90125-7

Waldstein, S. R., Rice, S. C., Thayer, J. F., Najjar, S. S., Scuteri, A., \& Zonderman, A. B. (2008). Pulse pressure and pulse wave velocity are related to cognitive decline in the Baltimore Longitudinal Study of Aging. Hypertension, 51(1), 99-104. 
Wardrop, R. M. (2014). Hypertension Awareness and Control Among Young Adults. AAP Grand Rounds, Vol. 32, pp. 29-29. https://doi.org/10.1542/gr.32-3-29

Warnert, E. A. H., Verbree, J., Wise, R. G., \& van Osch, M. J. P. (2016). Using High-Field Magnetic Resonance Imaging to Estimate Distensibility of the Middle Cerebral Artery. Neuro-Degenerative Diseases, 16(5-6), 407-410.

Watson, N. L., Sutton-Tyrrell, K., Rosano, C., Boudreau, R. M., Hardy, S. E., Simonsick, E. M., ... Newman, A. B. (2011a). Arterial stiffness and cognitive decline in well-functioning older adults. The Journals of Gerontology. Series A, Biological Sciences and Medical Sciences, 66(12), 1336-1342.

Weller, R. O., Yow, H.-Y., Preston, S. D., Mazanti, I., \& Nicoll, J. A. R. (2002). Cerebrovascular disease is a major factor in the failure of elimination of Abeta from the aging human brain: implications for therapy of Alzheimer's disease. Annals of the New York Academy of Sciences, 977, 162-168.

Wildman, R. P., Colvin, A. B., Powell, L. H., Matthews, K. A., Everson-Rose, S. A., Hollenberg, S., ... Sutton-Tyrrell, K. (2008). Associations of endogenous sex hormones with the vasculature in menopausal women: the Study of Women's Health Across the Nation (SWAN). Menopause, 15(3), 414-421.

Wu, J., Hadoke, P. W. F., Mair, I., Lim, W. G., Miller, E., Denvir, M. A., \& Smith, L. B. (2014). Modulation of neointimal lesion formation by endogenous androgens is independent of vascular androgen receptor. Cardiovascular Research, 103(2), 281-290.

Xing, C.-Y., Tarumi, T., Liu, J., Zhang, Y., Turner, M., Riley, J., ... Zhang, R. (2017).

Distribution of cardiac output to the brain across the adult lifespan. Journal of Cerebral Blood Flow and Metabolism: Official Journal of the International Society of Cerebral Blood Flow and Metabolism, 37(8), 2848-2856.

Yip, R., Johnson, C., \& Dallman, P. R. (1984). Age-related changes in laboratory values used in the diagnosis of anemia and iron deficiency. The American Journal of Clinical Nutrition, 39(3), 427-436.

Zaidi, Z. F. (2010). Gender Differences in Human Brain: A Review. The Open Anatomy Journal, Vol. 2, pp. 37-55. https://doi.org/10.2174/1877609401002010037

Zaninotto, P., Batty, G. D., Allerhand, M., \& Deary, I. J. (2018). Cognitive function trajectories and their determinants in older people: 8 years of follow-up in the English Longitudinal Study of Ageing. Journal of Epidemiology and Community Health, 72(8), 685-694.

Zeki Al Hazzouri, A., Newman, A. B., Simonsick, E., Sink, K. M., Sutton Tyrrell, K., Watson, N., ... Health ABC Study. (2013). Pulse wave velocity and cognitive decline in elders: the Health, Aging, and Body Composition study. Stroke; a Journal of Cerebral Circulation, 44(2), 388-393. 
Zhang, Z.-Z., Wang, P., Kong, X.-L., Mao, W.-L., \& Cui, M.-Y. (2019). Association of hemoglobin with arterial stiffness evaluated by carotid-femoral pulse wave velocity among Chinese adults. Chronic Diseases and Translational Medicine, 5(2), 122-128.

Zhong, W., Cruickshanks, K. J., Schubert, C. R., Carlsson, C. M., Chappell, R. J., Klein, B. E. K., ... Acher, C. W. (2014). Pulse wave velocity and cognitive function in older adults. Alzheimer Disease and Associated Disorders, 28(1), 44-49.

Zhu, Y.-S., Tarumi, T., Tseng, B. Y., Palmer, D. M., Levine, B. D., \& Zhang, R. (2013). Cerebral vasomotor reactivity during hypo- and hypercapnia in sedentary elderly and Masters athletes. Journal of Cerebral Blood Flow and Metabolism: Official Journal of the International Society of Cerebral Blood Flow and Metabolism, 33(8), 1190-1196. 